\title{
Investigation into gas lubrication performance of porous gas bearing considering velocity slip boundary condition
}

\author{
Xiangbo ZHANG ${ }^{1,2}$, Shuiting DING ${ }^{2,3}$, Farong DU ${ }^{2,3, *}$, Fenzhu $\mathbf{J I}^{4}$, Zheng $\mathbf{X U}^{1,2}$, Jiang LIU ${ }^{4}$, Qi ZHANG ${ }^{4}$, \\ Yu ZHOU ZH, $^{2, *}$ \\ ${ }^{1}$ School of Energy and Power Engineering, Beihang University, Beijing 100191, China \\ 2 Aircraft/Engine Integrated System Safety Beijing Key Laboratory, Beihang University, Beijing 100191, China \\ ${ }^{3}$ Research Institute of Aero-Engine, Beihang University, Beijing 100191, China \\ ${ }^{4}$ School of Transportation Science and Engineering, Beihang University, Beijing 100191, China \\ Received: 19 August 2020 / Revised: 27 January 2021 / Accepted: 17 February 2021 \\ (C) The author(s) 2021.
}

\begin{abstract}
Porous gas bearings (PGBs) have a proactive application in aerospace and turbomachinery. This study investigates the gas lubrication performance of a PGB with the condition of velocity slip boundary (VSB) owing to the high Knudsen number in the gas film. The Darcy-Forchheimer laws and modified Navier-Stokes equations were adopted to describe the gas flow in the porous layer and gas film region, respectively. An improved bearing experimental platform was established to verify the accuracy of the derived theory and the reliability of the numerical analysis. The effects of various parameters on the pressure distribution, flow cycle, load capacity, mass flow rate, and velocity profile are demonstrated and discussed. The results show that the gas can flow in both directions, from the porous layer to the gas film region, or in reverse. The load capacity of the PGB increases with an increase in speed and inlet pressure and decreases with an increase in permeability. The mass flow rate increases as the inlet pressure and permeability increase. Furthermore, the simulation results using VSB are in agreement with the experimental results, with an average error of $3.4 \%$, which indicates that the model using VSB achieves a high accuracy. The simulation results ignoring the VSB overrate the load capacity by $16.42 \%$ and undervalue the mass flow rate by $11.29 \%$. This study may aid in understanding the gas lubrication mechanism in PGBs and the development of novel gas lubricants.
\end{abstract}

Keywords: porous gas bearing (PGB); velocity slip boundary (VSB); numerical simulation; gas lubrication; flow characteristics

\section{Introduction}

Friction and wear are tribological phenomena that occur on surfaces that slide or roll over each other, resulting in a waste of energy and equipment damage. Many methods have been studied to reduce friction and avoid wear, one of which is gas lubrication. In the field of rotating machinery, the demand for high speed and high efficiency has promoted the development of oil-free gas bearings [1]. As a branch of gas bearings, porous gas bearings (PGBs) have been successfully applied in precision machine tools and fixtures [2]. Kumar [3] reported that Montgomery first published a study on PGBs in 1955. They proposed a pair of porous bearings to support a rotor that rotates at 250,000 rpm. Sneck [4] was the first to conduct a bibliographic review of porous aerostatic bearings in 1968, and presented the theory of PGBs, internal flow characteristics, load capacity, pressure distribution, and their applications. This was later updated by Majumdar [5] in 1976. These studies have laid down the fundamentals of PGBs. In terms of internal flows,

* Corresponding authors: Farong DU, E-mail: dfr@buaa.edu.cn; Yu ZHOU, E-mail: zybuaa@hotmail.com 


\begin{tabular}{|c|c|c|c|}
\hline \multicolumn{4}{|c|}{ Nomenclature } \\
\hline$C_{i j}$ & Inertial resistance coefficient matrix & $x, y, z$ & Cartesian coordinates \\
\hline$c_{p}$ & Constant pressure specific heat $(\mathrm{J} /(\mathrm{kg} \cdot \mathrm{K}))$ & $\alpha$ & Permeability factor \\
\hline$D_{i j}$ & Viscous resistance coefficient matrix & $\lambda$ & Mean free path $(\mathrm{mm})$ \\
\hline div & Divergeence sign & $l$ & Characteristic length (mm) \\
\hline$F$ & Volumetric force $(\mathrm{N})$ & $\sigma$ & Molecular diameter (mm) \\
\hline$h$ & Thickness of porous layer (mm) & $k$ & Boltzmann constant \\
\hline$L$ & Bearing length $(\mathrm{mm})$ & $\eta$ & Dynamic viscosity $\left((\mathrm{N} \cdot \mathrm{s}) / \mathrm{m}^{2}\right)$ \\
\hline$\nabla p_{i}$ & Internal pressure decrease of porous $(\mathrm{Pa})$ & $\rho$ & Gas density $\left(\mathrm{kg} / \mathrm{m}^{3}\right)$ \\
\hline$p$ & Pressure $(\mathrm{Pa})$ & $\mathbf{v}$ & Velocity component in Cartesian coordinates \\
\hline$m$ & Mass flow rate $(\mathrm{kg} / \mathrm{s})$ & & $(\mathrm{m} / \mathrm{s})$ \\
\hline $\mathrm{N}$ & Rotational speed (rpm) & $u, v, w$ & Velocity in the three directions of the Cartesian \\
\hline$R_{1}$ & Inner radius $(\mathrm{mm})$ & & coordinates $(\mathrm{m} / \mathrm{s})$ \\
\hline$R_{2}$ & Outer radius $(\mathrm{mm})$ & $\gamma$ & Porosity \\
\hline$U$ & Tangential velocity $(\mathrm{m} / \mathrm{s})$ & $\varphi_{x}, \varphi_{y}, \varphi$ & Viscous permeability $\left(\mathrm{m}^{2}\right)$ \\
\hline$V$ & Normal velocity (m/s) & $\psi_{x}, \psi_{y}, \psi$ & Inertial permeability $\left(\mathrm{m}^{2}\right)$ \\
\hline
\end{tabular}

one/two-dimensional analyses of the internal flows with a correction of the compressible flows have been conducted. In terms of load capacity, the influencing factors of the load capacity have been studied both theoretically and experimentally. Heller et al. [6] investigated a PGB used in miniature turbomachinery, which was subjected to a loading of $700 \mathrm{~g}$ and a speed of up to $65,000 \mathrm{rpm}$. Devitt et al. [7] investigated the possibility of PGBs supporting multi-megawatt rotating equipment. Ertas [8] discussed the advancements of gas bearings and concluded that more PGBs should be adopted in the next-generation turbomachinery.

In recent years, theoretical and computational progress of PGB has been achieved. Lee and You $[9,10]$ researched the influences of structural parameters on the PGB stability to solve nonlinear partial differential equations using a quasi-linear numerical programming method, which proved that the PGB is satisfactory for aerodynamic lubrication. To investigate the nonlinear characteristics of porous bearings, $\mathrm{Wu}$ et al. [2] presented a numerical nonlinear model to analyze the nonlinear characteristics of a rotor system with porous-type bearing support. Chang and Chen [11] investigated the nonlinear characteristics of a flexible rotor supported on two porous bearings. In their study, the rotor orbit and bifurcation diagrams that varied with the bearing parameters were analyzed. For detailed predictions of the bearing dynamic characteristics, Cui et al. [12, 13] analyzed the influence of bearing manufacturing errors on the dynamic characteristics, studied the operating accuracy of PGB based on moving grid technology, and verified the simulation results through testing. However, the gas film between the PGB and rotor become extremely small, being characterized at the micro- and nano-scales, and the actual surface of the porous layer cannot be smooth, where surface effects begin to dominate. Meanwhile, the gas flow through the porous layer matches the condition of the classical Darcy-Forchheimer law, whereas the velocity slip boundary (VSB) is applied at the surface of the porous layer, which directly affects the velocity gradient and the pressure distribution in the radial clearance of the PGBs. The classical no-slip velocity condition may be invalidated. The VSB has an essential impact on the flow transport and energy dissipation, which are crucial for many different applications [14].

A classification of flows into slip flows for gases can be made according to the Knudsen number, $K n$, defined as $K n=\lambda / l$, where $\lambda$ is the mean free molecular path and $l$ is the characteristic fluid thickness. For $K n>0.1$, Nicoletti et al. [15] suggested that there is no need to consider the slip, and proposed a 
modified version of the quadratic Forchheimer model to investigate the performances of PGBs by solving the Reynolds equation. Rao et al. [16] theoretically investigated the influence of the permeability of porous layer and structural parameters on the bearing performance. Both the theoretical and experimental results show that PGBs achieve satisfactory dynamic characteristics. However, at $0.001<K n \leq 0.1$, which is consistent with the $K n$ range applied in this study, the velocity slip should be considered. Prakash and Gururajan [17] analyzed the effect of VSB in an infinitely long porous oil journal bearing, which indicated that VSB decreases the bearing load capacity. In addition, Kalavathi et al. [18] proposed a numerical method to investigate the effects of the slip parameters on a porous finite journal with a slip/no-slip surface, which revealed a strong relationship between the VSB and lubrication performance. Compared with different $K n$ ranges, it can be concluded that a porous bearing has a uniform pressure distribution, high load capacity, simple structure, and convenient manufacturing process. The main difference is whether the VSB should be considered. Compared with the same $K n$ range, previous studies have mainly focused on oil lubrication or other liquid porous media bearings, whereas studies on PGBs with VSB have been limited. By contrast, research on VSB has been carried out in rarefied gas flows and microchannel devices. To numerically evaluate the slip in rarefied gas flows, Le et al. [19] selected four types of aerodynamic configurations with $K n$ varying from 0.004 to 0.07 . Jebauer and Czerwińska [20] studied the boundary conditions of microfluidic devices. Although the above investigations have made significant contributions toward the development of porous media bearings and velocity slip boundaries, they have mainly focused on liquid porous media bearings. There is insufficient research on gas porous media bearings with VSB, particularly the variation of the load capacity and mass flow rate under different operational conditions and design parameters. Moreover, the flow cycle, pressure distribution, and velocity profile within the fluid domain must be further investigated.

The novelty of this study is an investigation into the gas lubrication performance of PGB with VSB, including the flow characteristics, load capacity, mass flow rate, pressure distribution, and velocity vector inside the porous layer and gas film region. In addition, an experimental platform was established. The load capacity and mass flow rate were tested at different speeds, inlet pressures, and permeabilities. The results indicate that the simulation model with the VSB is in good agreement with the experimental results. The remainder of this paper is organized as follows. Section 2 describes the geometric model, governing equations, and the simulation model applied. Section 3 presents the simulation and provides a discussion of the influence of various parameters on the PGB. Section 4 describes the test platform and compares the experimental and simulation results. Finally, some concluding remarks are presented in Section 5.

\section{Model description}

\subsection{Geometric model}

A schematic of the structure of the PGB and rotor is shown in Fig. 1, which is composed of a bearing sleeve, porous layer, and rotor. The porous layer is a sintered material that can be manufactured with different porosity structures and materials using powder metallurgical techniques. The pressurized gas enters the gas chamber through a small hole manufactured in the bearing sleeve. The pressurized gas enters the gas chamber with a consistent pressure and then flows into the gap between the porous layer and rotor through the micropores of the porous layer. The gas in the gap forms a uniform gas film and provides reliable support to the rotor. The gas flow is illustrated in Fig. 2. Table 1 lists the detailed geometric parameters of the PGB.

\subsection{Governing equations}

In theory, the gas in the porous layer and gas film

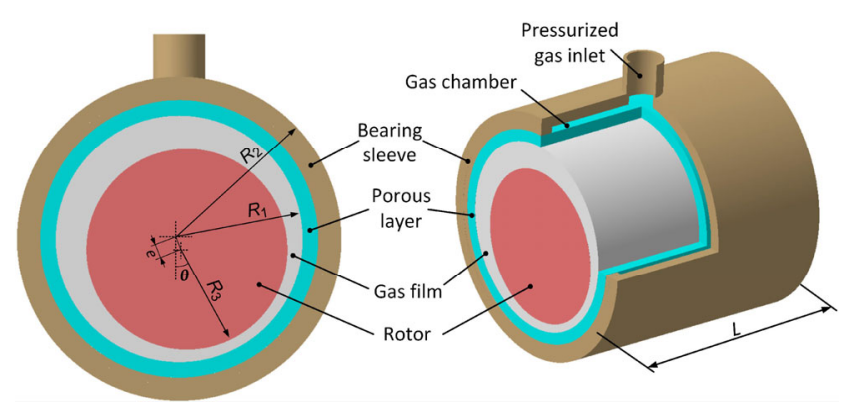

Fig. 1 Structural schematic of PGB and rotor. 


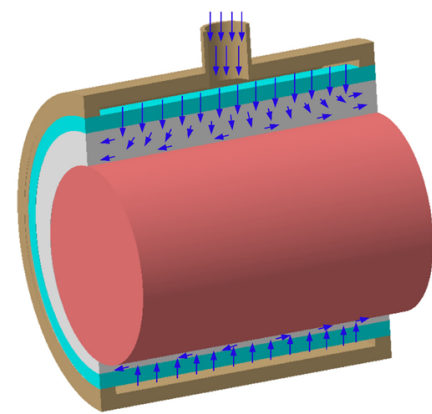

Fig. 2 Schematic of gas flow.

Table 1 Main geometric parameters of PGB.

\begin{tabular}{cc}
\hline Parameter & Value \\
\hline Inner radius, $R_{1}(\mathrm{~mm})$ & 14 \\
Outer radius, $R_{2}(\mathrm{~mm})$ & 19 \\
Bearing length, $L(\mathrm{~mm})$ & 42 \\
Porous length, $L(\mathrm{~mm})$ & 42 \\
Porous thickness, $h(\mathrm{~mm})$ & 5 \\
\hline
\end{tabular}

satisfies the Darcy-Forchheimer laws and modified Navier-Stokes equations, respectively [21, 22]. Its flow characteristics, pressure distribution, velocity distribution, and velocity vectors are affected by parameters such as the speed, inlet pressure, and permeability. To obtain these properties, it is necessary to make the assumptions listed below [23]. Meanwhile, all experiments and a solving of the governing equations in this study were carried out under the condition that the intake gas temperature was lower than $334 \mathrm{~K}$ [24].

1) The gas flow satisfies the ideal gas law.

2) The viscous resistance coefficient of the gas is constant and does not vary with temperature.

3) The permeability of the porous material was constant and did not change with temperature.

The flow through a porous layer obeys the DarcyForchheimer laws. The pressure drop inside the porous layer can be expressed as follows [25]:

$$
\nabla p_{i}=-\left(\sum_{j=1}^{3} D_{i j} \eta v_{i}+\sum_{j=1}^{3} C_{i j} \frac{1}{2} \rho\left|v_{i}\right| v_{i}\right)
$$

where $\nabla p_{i}$ is the internal pressure drop of a porous layer; $D_{i j}$ and $C_{i j}$ are the resistance coefficient matrixes of the viscosity and inertia, respectively; $\eta$ is the dynamic viscosity; $\rho$ is the gas density; and $v_{i}$ is the velocity vector, in which $i$ can take values of 1,2 , or 3, and represent the $x-, y$-, and $z$-directions in the Cartesian coordinates, respectively. The ranges of $j$ are 1,2 , and 3 . The viscous and inertial resistance coefficient matrices can be written in the following form:

$$
\begin{aligned}
D_{i j} & =\left[\begin{array}{ccc}
\frac{1}{\varphi_{x}} & 0 & 0 \\
0 & \frac{1}{\varphi_{y}} & 0 \\
0 & 0 & \frac{1}{\varphi_{z}}
\end{array}\right] \\
C_{i j} & =\left[\begin{array}{ccc}
\frac{1}{\psi_{x}} & 0 & 0 \\
0 & \frac{1}{\psi_{y}} & 0 \\
0 & 0 & \frac{1}{\psi_{z}}
\end{array}\right]
\end{aligned}
$$

where $\varphi_{x}, \varphi_{y}, \varphi_{z}, \psi_{x}, \psi_{y}$, and $\psi_{z}$ are the viscous and inertial permeability in three directions of Cartesian coordinates, respectively, which can be determined through experiments or empirical formulas.

The mass conservation equation in a porous layer is as follows:

$$
\frac{\partial \rho}{\partial t}+\frac{\partial(\rho u)}{\partial x}+\frac{\partial(\rho v)}{\partial y}+\frac{\partial(\rho w)}{\partial z}=0
$$

where $u, v$, and $w$ are the gas velocities in the directions of the Cartesian coordinates $x, y$, and $z$, respectively.

By combining the gas state equation [26], the gas pressure inside the porous layer can be obtained through the following equation:

$$
\frac{\partial(\rho \mathbf{v})}{\partial t}+\operatorname{div}(\rho \mathbf{v} \times \mathbf{v})+\nabla p+D_{i j} \mu \mathbf{v}+\frac{1}{2} C_{i j} \rho|\mathbf{v}| \mathbf{v}=0
$$

where div is the divergence sign.

In the gas film of the rotor and PGB, a gas flow is also limited by the mass conservation, momentum conservation, and energy conservation, which can be expressed through the Navier-Stokes equations [27-29].

According to Newton's second law, the conservation of momentum in the $x-, y-$, and $z$-directions is as 
follows:

$$
\begin{aligned}
& \frac{\partial(\rho u)}{\partial t}+\operatorname{div}(\rho v u)=-\frac{\partial p}{\partial x}+\frac{\partial \tau_{x x}}{\partial x}+\frac{\partial \tau_{y x}}{\partial y}+\frac{\partial \tau_{z x}}{\partial z}+F_{x} \\
& \frac{\partial(\rho v)}{\partial t}+\operatorname{div}(\rho v v)=-\frac{\partial p}{\partial y}+\frac{\partial \tau_{x y}}{\partial x}+\frac{\partial \tau_{y y}}{\partial y}+\frac{\partial \tau_{z y}}{\partial z}+F_{y} \\
& \frac{\partial(\rho w)}{\partial t}+\operatorname{div}(\rho v w)=-\frac{\partial p}{\partial z}+\frac{\partial \tau_{x z}}{\partial x}+\frac{\partial \tau_{y z}}{\partial y}+\frac{\partial \tau_{z z}}{\partial z}+F_{z}
\end{aligned}
$$

where $p$ is the pressure, $F_{x}, F_{y}$, and $F_{z}$ are the volumetric forces in the three directions of Cartesian coordinates, respectively, and $\tau$ is the viscous stress.

The energy conservation equation is as follows:

$$
\frac{\partial(\rho T)}{\partial t}+\operatorname{div}(\rho \mathbf{v} T)=\operatorname{div}\left(\frac{k}{c_{p}} \operatorname{grad} T\right)+S_{T}
$$

where $T$ is the temperature, $c_{p}$ is the specific heat capacity, $k$ is the heat transfer coefficient, grad $T$ is the temperature gradient, and $S_{T}$ is the viscous dissipation energy.

A phenomenon known as the velocity slip boundary condition could emerge as the flow geometries scaled down to the micro-/nano-scales. Under these conditions, the surface boundary conditions become increasingly dominant. New features of the flow in small gaps, such as a gas film between the rotor and PGB, can arise. The characteristics are determined using the $K n$ [30]. The following should be noted: A) The flows with $K n \leq 0.001$ are regarded as noslip flows, B) $0.001<K n \leq 0.1$ are slip flows, C) $0.1<$ $K n \leq 10$ are flows in the transitional regime, and D) $K n>10$ are considered free molecular flows [20, 31-33]. Ma and Luo [34] and Gao et al. [35] summarized and reviewed the development of thin film lubrication during the past 20 years and explored the molecular orientation and friction performance in the contact region with a gap size of $10 \mathrm{~s}$ of nanometers. The $\mathrm{Kn}$ number researched in this study is between 0.001 and 0.1 , and the flow of the gas film is a slip flow. The Navier-Stokes equations can be applied to a slip flow unless appropriate boundary conditions are provided. References [36, 37] proposed some boundary conditions. Maxwell's equation [20] is used to estimate the slip coefficient of rough walls based on classical theory, which is adopted to calculate the velocity slip boundary condition as follows:

$$
\begin{aligned}
u_{\mathrm{s}}= & \left(1-l_{k}^{2}\right) U_{0}+\frac{2-\sigma_{t}}{\sigma_{t}} \lambda\left\{\frac{\partial}{\partial y_{k}}\left[\left(1-l_{k}^{2}\right) u-l_{k} m_{k} v-l_{k} n_{k} w\right]\right. \\
& \left.+\left(1-l_{k}^{2}\right) \frac{\partial v_{k}}{\partial y}-l_{k} m_{k} \frac{\partial v_{k}}{\partial y}-l_{k} n_{k} \frac{\partial v_{k}}{\partial y}\right\} \\
v_{\mathrm{s}}= & \frac{2-\sigma_{t}}{\sigma_{t}} \lambda\left\{\frac{\partial}{\partial y_{k}}\left[\left(1-m_{k}^{2}\right) v-l_{k} m_{k} u-m_{k} n_{k} w\right]\right. \\
& \left.+\left(1-m_{k}^{2}\right) \frac{\partial v_{k}}{\partial y}-l_{k} m_{k} \frac{\partial v_{k}}{\partial y}-m_{k} n_{k} \frac{\partial v_{k}}{\partial y}\right\} \\
w_{\mathrm{s}}= & \frac{2-\sigma_{t}}{\sigma_{t}} \lambda\left\{\frac{\partial}{\partial y_{k}}\left[\left(1-n_{k}^{2}\right) u-l_{k} n_{k} v-m_{k} n_{k} v\right]\right. \\
& \left.+\left(1-n_{k}^{2}\right) \frac{\partial v_{k}}{\partial z}-l_{k} m_{k} \frac{\partial v_{k}}{\partial x}-m_{k} n_{k} \frac{\partial v_{k}}{\partial y}\right\}
\end{aligned}
$$

where $V_{s}=\left(u_{s}, v_{s}, w_{s}\right)$ is the slip velocity of the gas on a rough wall, $U_{0}$ is the velocity of the moving wall, and $u, v, w$ represent the velocities of the gas near the wall, respectively. In addition, $k$ is the grid unit. $v_{k}=l_{k} u+m_{k} v+n_{k} w, \partial / \partial y_{k}=l_{k} \partial / \partial x+m_{k} \partial / \partial y+n_{k} \partial / \partial z$, and $L=\left(l_{k}, m_{k}, n_{k}\right)$ is the unit normal vector of the grid on the wall.

We can then obtain the pressure distribution in the porous layer, the velocity distribution, and the vectors in the gas film between the PGB and the rotor by solving the above equations simultaneously.

\subsection{Simulation model}

The PGB is an axisymmetric structure that can be divided along the axial symmetrical plane, using half to simulate the performance of the PGB. The simulation domain can be divided into a gas-film zone and a porous zone. The gas film zone is between the rotor and the PGB, and the porous region is considered a rigid volume. The two zones (gas film and porous layer) were discretized using a grid. The grid model and boundary conditions are illustrated in Fig. 3.

The hexahedral structured grid can improve the matching degree between the grid model and the geometric model $[38,39]$. Therefore, we discretized the fluid domain into this structured grid. To avoid the influence of the grid number on the calculation results, three grid configurations were used to test grid convergence. The numbers of grid cases are listed in Table 2. Taking case B as the reference case, the total load acting on the rotor was chosen as the global variable to determine whether grid convergence was 


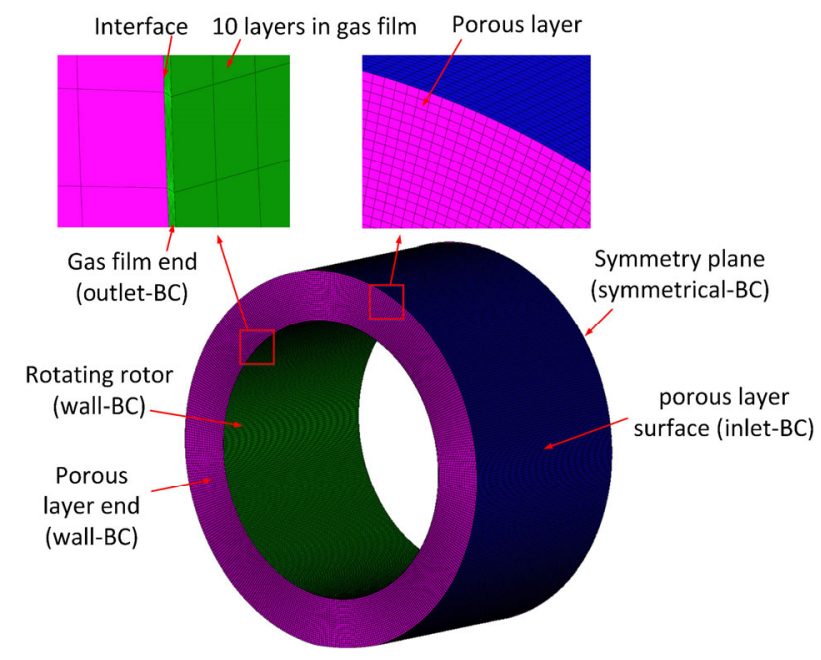

Fig. 3 Grid model and boundary conditions (BCs).

Table 2 Proof of grid independence.

\begin{tabular}{ccc}
\hline Number of grids & Total load on the rotor & Error (\%) \\
\hline Case A 1,064,100 & 68.58 & -3.68 \\
Case B 1,597,200 & 71.20 & - \\
Case C 2,395,800 & 72.35 & 1.62 \\
\hline
\end{tabular}

achieved. The results are shown in Table 2, which indicates good convergence for around 1,597,200 grids, leading to case $\mathrm{B}$ being chosen for all computations.

In the radial direction, 10-layer grids were employed in the gas film, and 25 layers were utilized in the porous layer. A total of 440 and 105 layers were applied in the circumferential and axial directions, respectively. Symmetrical boundary conditions are introduced along the axial symmetry plane of the porous layer and gas film, where the axial pressure and velocity gradients are zero, which is similar to the periodic boundary condition used in Ref. [40]. Gas leakage was not allowed in the porous layer end. Thus, the end is set as a "wall" boundary condition, and the outer surface of the porous layer is the pressure inlet. The rotor is a rigid body with a certain angular velocity, the surface of which is also set as a "wall". The end of the gas film was the pressure outlet boundary. The interface was set at the junction of the porous layer and the gas film, where the velocity, shear force, and pressure are continuous, and the mass is conserved.

As mentioned above, the governing equations of PGB are nonlinear partial differential equations, which makes it difficult to obtain the exact solution using an analytical method. Therefore, the simulation method is adopted to obtain the solution using the commercial software ANSYS FLUENT, which has advantages in the macroscopic visualization of the flow field. It can solve turbulence equations and capture the complex flow near the boundary layer [41, 42]. In addition, the pore characteristics, the viscous and inertial resistance coefficients, and the velocity slip on the interface can also be considered in FLUENT. The finite volume method is utilized to solve the Darcy-Forchheimer law inside the porous layer and the full Navier-Stokes equations in the gas film, respectively [43, 44]. A semi-implicit algorithm based on pressure coupling equations (SIMPLE) was applied to solve the fluid domain. The second-order upwind style was used for the density, momentum, and turbulent flow energy. When the mass, momentum, and turbulence residuals were less than $1 \times 10^{-5}$, and the energy residuals were less than $1 \times 10^{-7}$, the convergence condition was considered to be achieved. The detailed parameters for the numerical calculation are shown in Table 3.

A user-defined function was applied to the velocity slip calculation [45]. The $i$-th iteration of the velocity slip is $u_{s}{ }^{i}, v_{s}{ }^{i}, w_{s}{ }^{i}$, and a new flow field can be procured by the finite volume method. Then, the new slip velocity $u_{s}^{n}, v_{s}^{n}, w_{s}^{n}$ can be easily calculated

Table 3 Detail parameters for numerical calculation.

\begin{tabular}{cc}
\hline Item & Value \\
\hline Solver & $\begin{array}{c}\text { Absolute steady } \\
\text { pressure-based }\end{array}$ \\
Solution method & SIMPLE \\
Solution initialization & Hybrid initialization \\
Viscous & Laminar \\
Gas & Ideal-gas \\
Air temperature $(\mathrm{K})$ & $1.789 \times 10^{-5}$ \\
Air constant $(\mathrm{J} /(\mathrm{kg} \cdot \mathrm{K}))$ & 300 \\
Inlet pressure $($ absolute $)(\mathrm{MPa})$ & $0.2,0.3,0.4,0.5$ \\
Outlet pressure $($ absolute $)(\mathrm{MPa})$ & 0.1 \\
Rotational speed $(\mathrm{rpm})$ & $20,000,40,000$, \\
& $70,000,100,000$ \\
Bearing diameter $($ mm $) \times$ length $(\mathrm{mm})$ & $28 \times 42 \times 5$ \\
$\times$ porous thickness $(\mathrm{mm})$ & 42 \\
Porous length $(\mathrm{mm})$ &
\end{tabular}


according to Eq. (9). The $(i+1)$-th iteration can be expressed as follows:

$$
\begin{aligned}
& u_{\mathrm{s}}^{i+1}=(1-\alpha) u_{\mathrm{s}}^{i}+\alpha u_{\mathrm{s}}^{n} \\
& v_{\mathrm{s}}^{i+1}=(1-\alpha) v_{\mathrm{s}}^{i}+\alpha v_{\mathrm{s}}^{n} \\
& w_{\mathrm{s}}^{i+1}=(1-\alpha) w_{\mathrm{s}}^{i}+\alpha w_{\mathrm{s}}^{n}
\end{aligned}
$$

where $\alpha$ is the under relaxation factor.

\section{Simulation and discussion}

\subsection{Influence of rotational speed on pressure distribution in the fluid domain}

To investigate the effect of the rotating speed on the pressure distribution of the PGB with VSB, the structural parameters remain unchanged. In addition, the radial clearance is $20 \mu \mathrm{m}$, eccentricity ratio is 0.5 , inlet pressure is $0.5 \mathrm{MPa}$, ambient pressure is $0.1 \mathrm{MPa}$, slip velocity is calculated using Eq. (9), and the permeability is $1 \times 10^{-14} \mathrm{~m}^{2}$.

Figure 4 shows the pressure distributions on the gas film and the axial middle section of the porous layer at different speeds. The right end is a pressure outlet, where the pressure is $0.1 \mathrm{MPa}$. The left end is an axial symmetry plane. As shown in Fig. 4(a), there was a pressure gradient inside the porous layer, indicating that pressure losses were produced in the porous layer. The eccentric rotation of the rotor squeezes the gas and forms a high-pressure zone on the gas film, which supports the rotor. The closer it is to the symmetry plane, the higher the pressure. From

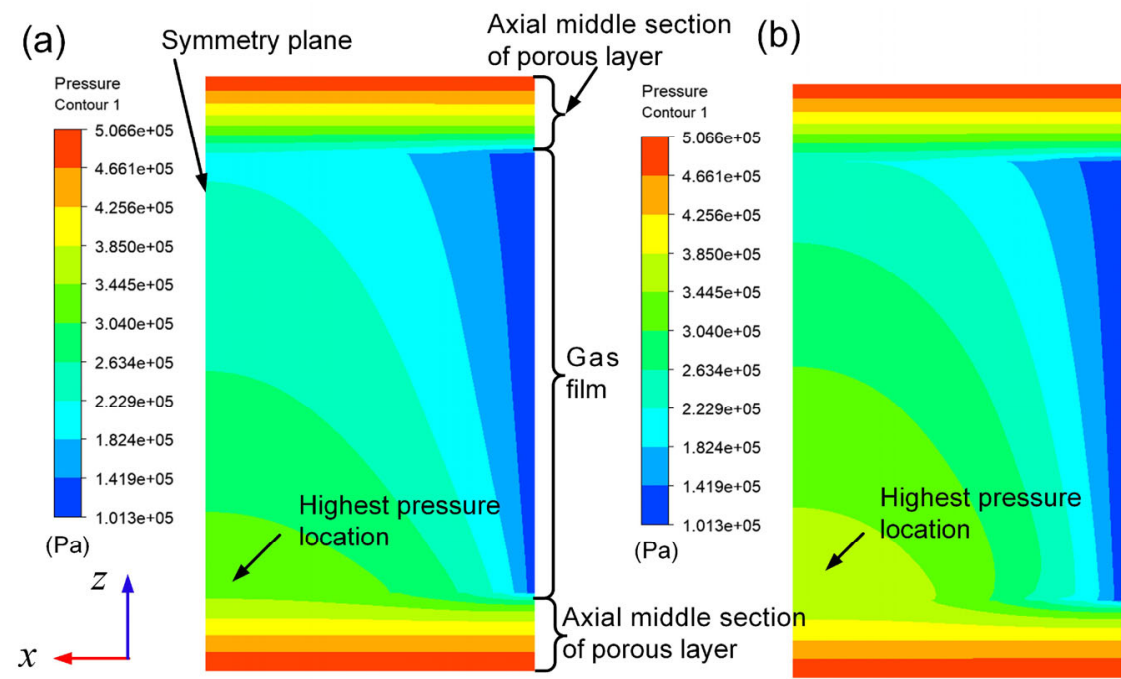

(c)

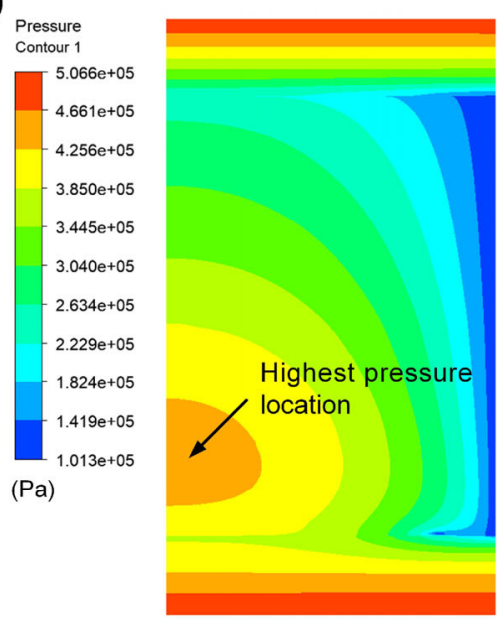

(d)

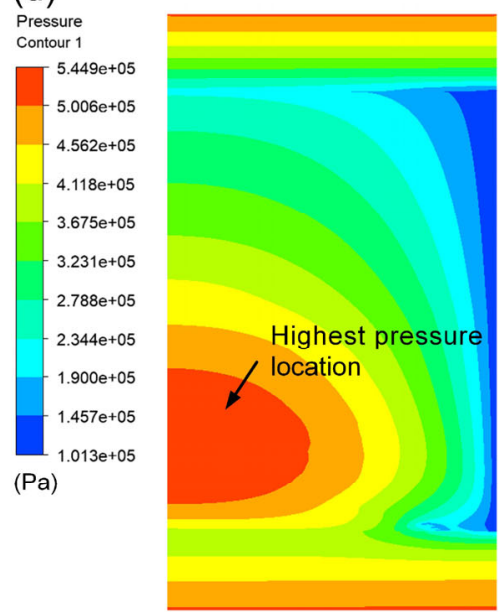

Fig. 4 Effect of speed on pressure distribution in gas film and axial middle section of the porous layer: (a) 20,000 rpm; (b) 40,000 rpm; (c) 70,000 rpm; (d) 100,000 rpm. 
Figs. 4(a)-4(d), the pressure gradient in the porous layer decreases with an increase in the rotational speed, and the width of the high-pressure region of the gas film significantly increases. Meanwhile, the attitude angle corresponding to the highest pressure also increases as the rotational speed increases. The hydrodynamic pressure compensates for the pressure loss and improves the load capacity.

The influence of the rotating speed on a threedimensional (3D) pressure distribution in a gas film can be analyzed, which finally acts on and supports the rotor [46]. According to the simulation results, the $3 \mathrm{D}$ pressure distributions in the gas film along the circumferential and axial directions are shown in Fig. 5. The axial end of the gas film was the outlet boundary, and the other end was a symmetrical boundary. As shown in Fig. 5(a), the speed was $20,000 \mathrm{rpm}$, the maximum pressure was $0.3 \mathrm{MPa}$, which was lower than the inlet pressure of $0.5 \mathrm{MPa}$, and the pressure drop was $0.2 \mathrm{MPa}$. The pressure transition between high pressure and low pressure was uniform, without a pressure peak. As the rotational speed increased, the maximum pressure in the gas film increased, indicating that the rotating rotor produced a significant hydrodynamic pressure.

\subsection{Influence of permeability on pressure distri- bution in fluid domain}

Permeability is an important parameter that describes the ability of gas flow through a porous layer and affects the pressure distribution in the porous layer and gas film [47]. Therefore, it is necessary to study the influence of different permeabilities on the pressure distribution. Some methods for measuring the permeability of porous materials have been presented $[48,49]$. The permeability can be expressed through the following equation for viscous and compressible gases [50, 51].

$$
K=\frac{2 \mu H P_{2}}{A\left(P_{1}^{2}-P_{2}^{2}\right)} Q
$$

where $K$ is the permeability, $\mu$ is the gas dynamic viscosity, $H$ is the thickness of a porous material, $Q$ is the volume flow through a porous material, $A$ is the cross-sectional area of a porous material along the gas flow direction, and $P_{1}$ and $P_{2}$ are the inlet and outlet pressures of a porous material, respectively. (a)

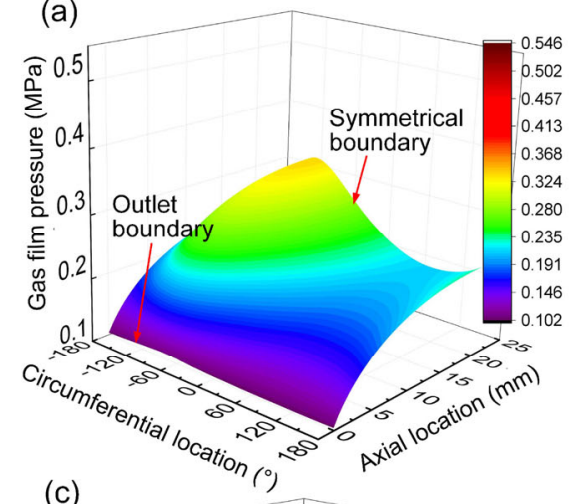

(c)

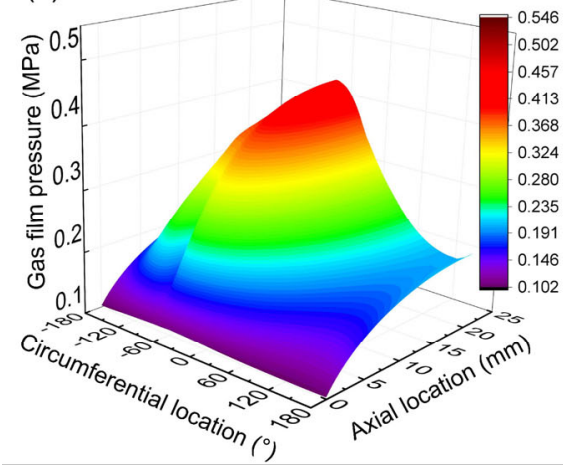

(b)
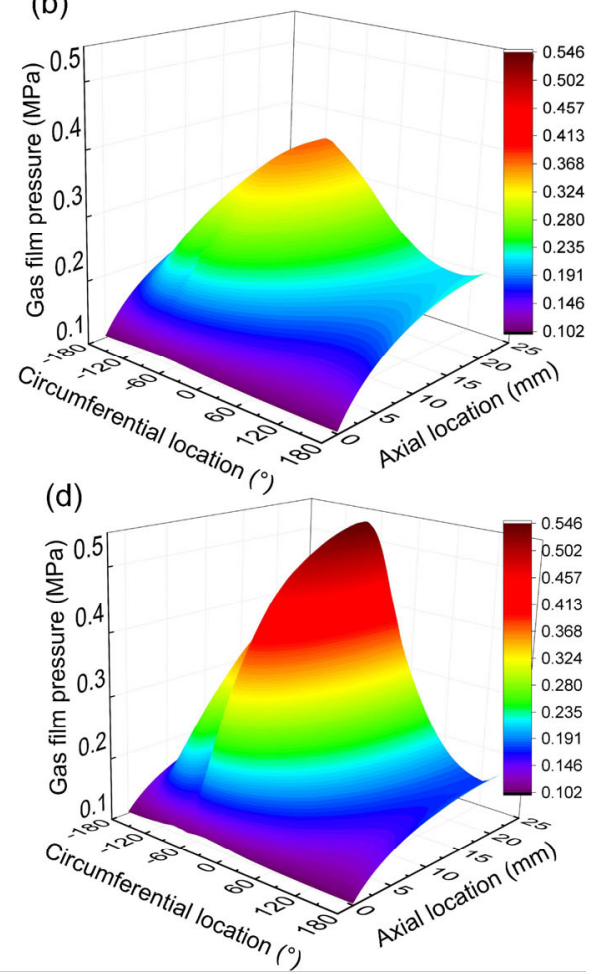

Fig. 5 Effect of speed on gas film pressure distribution: (a) 20,000 rpm; (b) 40,000 rpm; (c) 70,000 rpm; (d) 100,000 rpm. 
The schematic diagram and test rig used to obtain the permeability are shown in Figs. 6(a) and 6(b), respectively. A typical measurement method was used in this study, where the experiments were conducted in a certain system, and the pressure and volume flow rate were measured. The measured porous graphite material densities were 1.617, 1.673, and $1.709 \mathrm{~g} / \mathrm{cm}^{3}$, respectively. The size of the specimen was $34 \mathrm{~mm} \times$ $34 \mathrm{~mm}$, and its thickness was $3 \mathrm{~mm}$. Pressurized gas enters the measuring device, where the porous material is sealed, and then flows into the environment. The pressure and volume flow were measured using a pressure sensor and flowmeter, respectively. The test results of the inlet pressure and volume flow of the three different porous materials were obtained. The permeability can be calculated using Eq. (10). Based on the results of repeated experiments, the average permeabilities of the three porous graphite materials were $1 \times 10^{-12}, 1 \times 10^{-13}$, and $1 \times 10^{-14} \mathrm{~m}^{2}$, respectively. The permeability obtained from the test was used as the input parameter for the CFD simulation, which enhanced the reliability of the results.

When the inlet pressure is $0.5 \mathrm{MPa}$, gas film is $20 \mu \mathrm{m}$, eccentricity ratio is 0.5 , external environmental pressure is $0.1 \mathrm{MPa}$, rotor speed is $2 \times 10^{4}$ and $6 \times 10^{4} \mathrm{rpm}$, and the pressure variation in axial middle section of a porous layer and a gas film under different permeabilities are discussed. The results are shown in Figs. 7 and 8.

Figure 7 demonstrates that the higher the permeability is, the closer the internal pressure of the porous layer to the inlet pressure. By contrast, the lower the permeability, the higher the viscous resistance loss of the gas, and the more obvious the pressure gradient inside the porous layer. Owing to the low outlet pressure, there existed a pressure drop near the exit. As the rotating speed increases, the high-pressure region formed by the eccentric rotation was more significant, and the hydrodynamic pressure was more evident in the low-permeability porous material.

In Fig. 8, the pressure at the outlet boundary is close to the external pressure, and the pressure reaches its maximum value near the symmetric boundary. At the same speed, as the permeability increases, the pressure increases and is close to the inlet pressure. The pressure distribution in the circumferential direction was uniform. When the permeability is $1 \times 10^{-13}$ or $1 \times 10^{-12} \mathrm{~m}^{2}$, there is no clear distinction between the high-pressure and low-pressure areas. A uniform pressure distribution is not conducive to the load capacity of the PGB. The load capacity mainly depends on the pressure difference in the circumferential direction of the gas film. However, for a thrust bearing, a high uniform pressure can increase the load capacity. To ensure an adequate load capacity, the permeability must be appropriately selected. At the same permeability, the higher the speed, the higher the hydrodynamic pressure, which increases the maximum pressure in the gas film.

\subsection{Velocity vectors and velocity distribution in the fluid domain}

When the eccentricity is 0.5 , the permeability is $1 \times 10^{-14} \mathrm{~m}^{2}$, and the rotating speed is $2 \times 10^{4} \mathrm{rpm}$, Fig. 9 clearly shows the velocity vectors of the symmetrical (a)

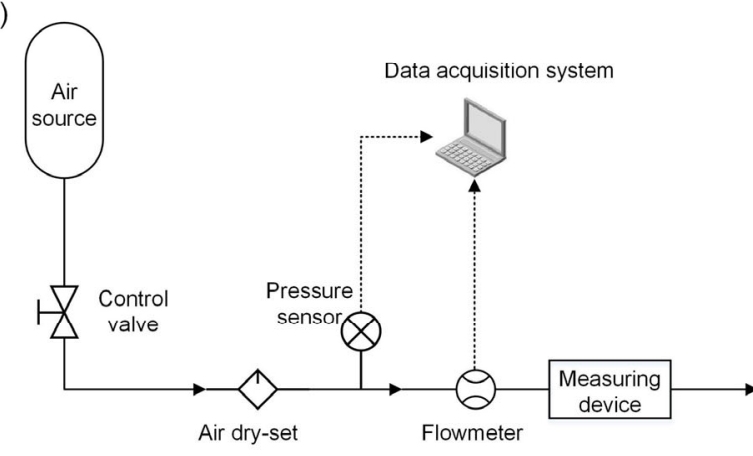

(b)

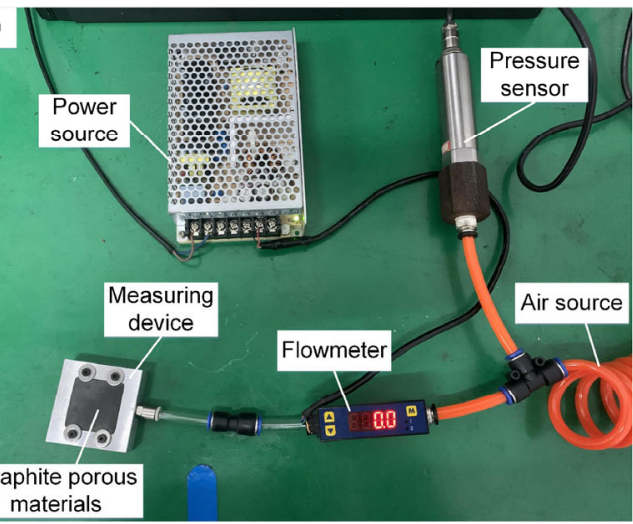

Fig. 6 Schematic diagram and test rig: (a) the schematic diagram and (b) the test rig. 
(a)

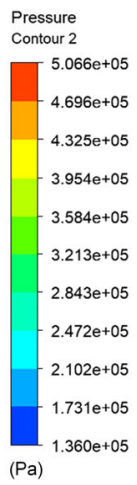

(d)

Pressure
Contour 2

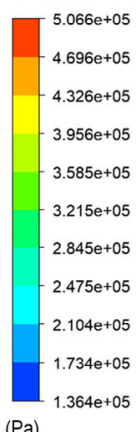

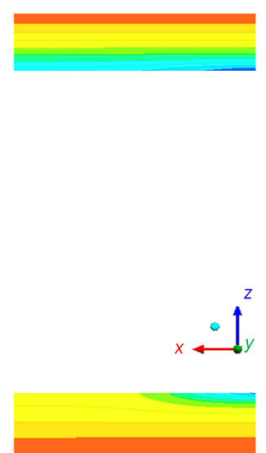

(b)

Pressure

Contour 2

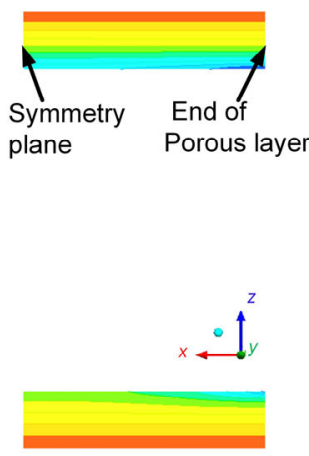

$-5.066 \mathrm{e}+05$
$-439 \mathrm{e}+05$
$-4.411 \mathrm{e}+05$
$-4.084 \mathrm{e}+05$
$3.757 \mathrm{e}+05$
$-3.429 \mathrm{e}+05$
$-3.102 \mathrm{e}+05$
$2.774 \mathrm{e}+05$
$2.447 \mathrm{e}+05$
$2.120 \mathrm{e}+05$
$1.792 \mathrm{e}+05$

(e)

\section{Pressure
Contour 2}

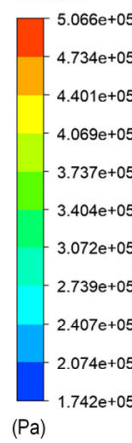

(c)

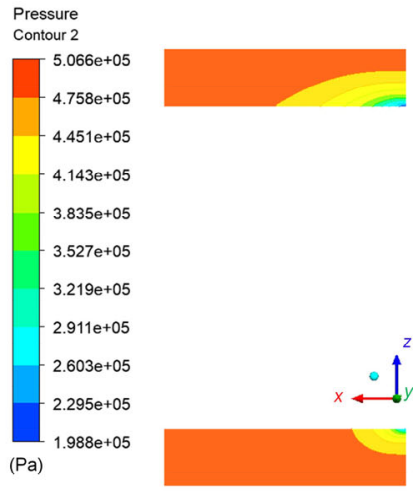

Fig. 7 Influence of permeability and speed on pressure distribution of axial middle section of the porous layer: (a) speed $=20,000 \mathrm{rpm}$, $K=1 \times 10^{-14} \mathrm{~m}^{2}$; (b) speed $=20,000 \mathrm{rpm}, K=1 \times 10^{-13} \mathrm{~m}^{2}$; (c) speed $=20,000 \mathrm{rpm}, K=1 \times 10^{-12} \mathrm{~m}^{2} ;(\mathrm{d}) \mathrm{speed}=60,000 \mathrm{rpm}, K=$ $1 \times 10^{-14} \mathrm{~m}^{2}$; (e) speed $=60,000 \mathrm{rpm}, K=1 \times 10^{-13} \mathrm{~m}^{2}$; (f) speed $=60,000 \mathrm{rpm}, K=1 \times 10^{-12} \mathrm{~m}^{2}$.

(a)

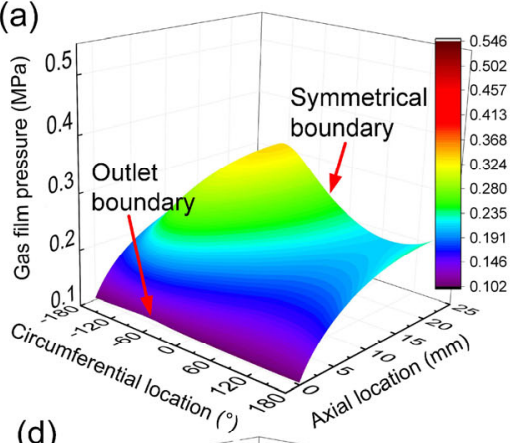

(d)

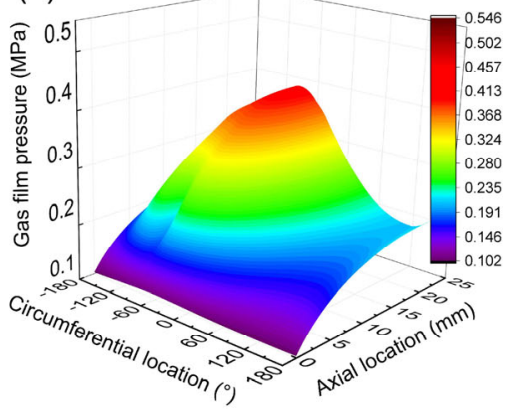

(b)

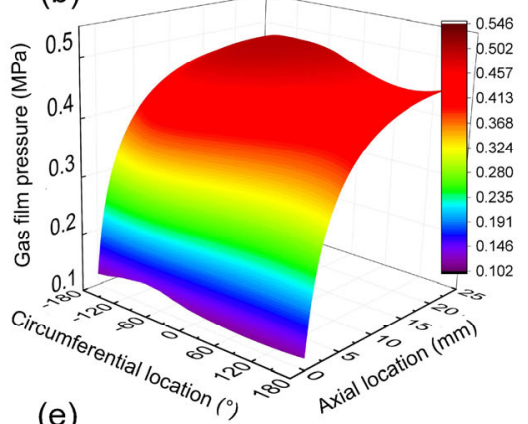

(e)

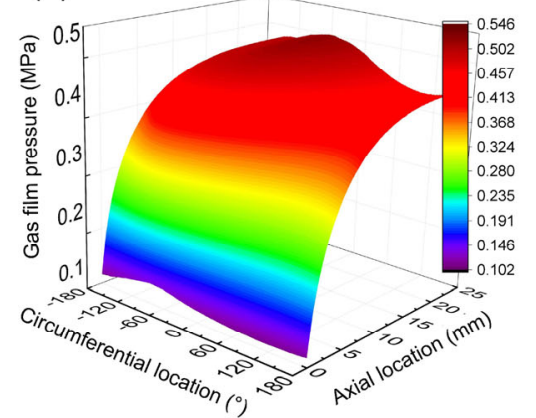

(c)
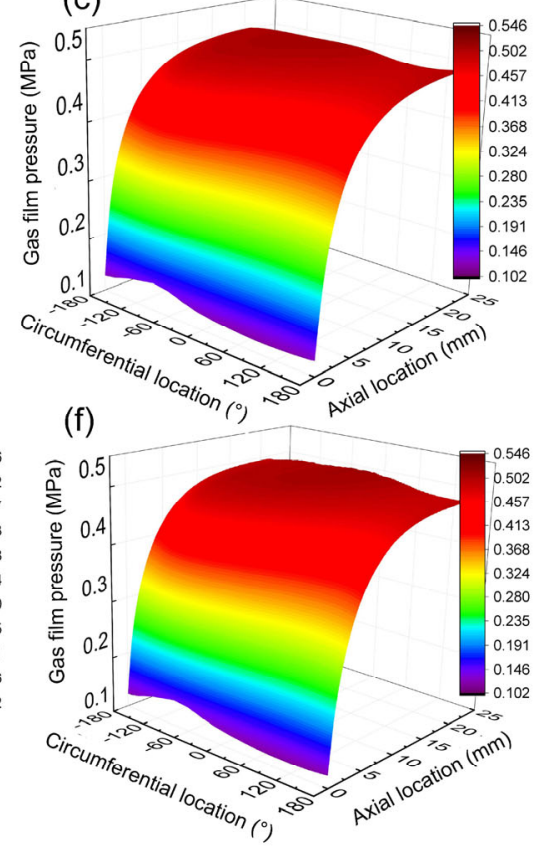

Fig. 8 Influence of permeability and speed on gas film pressure distribution: (a) speed $=20,000 \mathrm{rpm}, K=1 \times 10^{-14} \mathrm{~m}^{2}$; (b) $\mathrm{speed}=$ $20,000 \mathrm{rpm}, K=1 \times 10^{-13} \mathrm{~m}^{2}$; (c) speed $=20,000 \mathrm{rpm}, K=1 \times 10^{-12} \mathrm{~m}^{2}$; (d) speed =60,000 rpm, $K=1 \times 10^{-14} \mathrm{~m}^{2}$; (e) speed $=60,000 \mathrm{rpm}$, $K=1 \times 10^{-13} \mathrm{~m}^{2}$; (f) speed $=60,000 \mathrm{rpm}, K=1 \times 10^{-12} \mathrm{~m}^{2}$. 

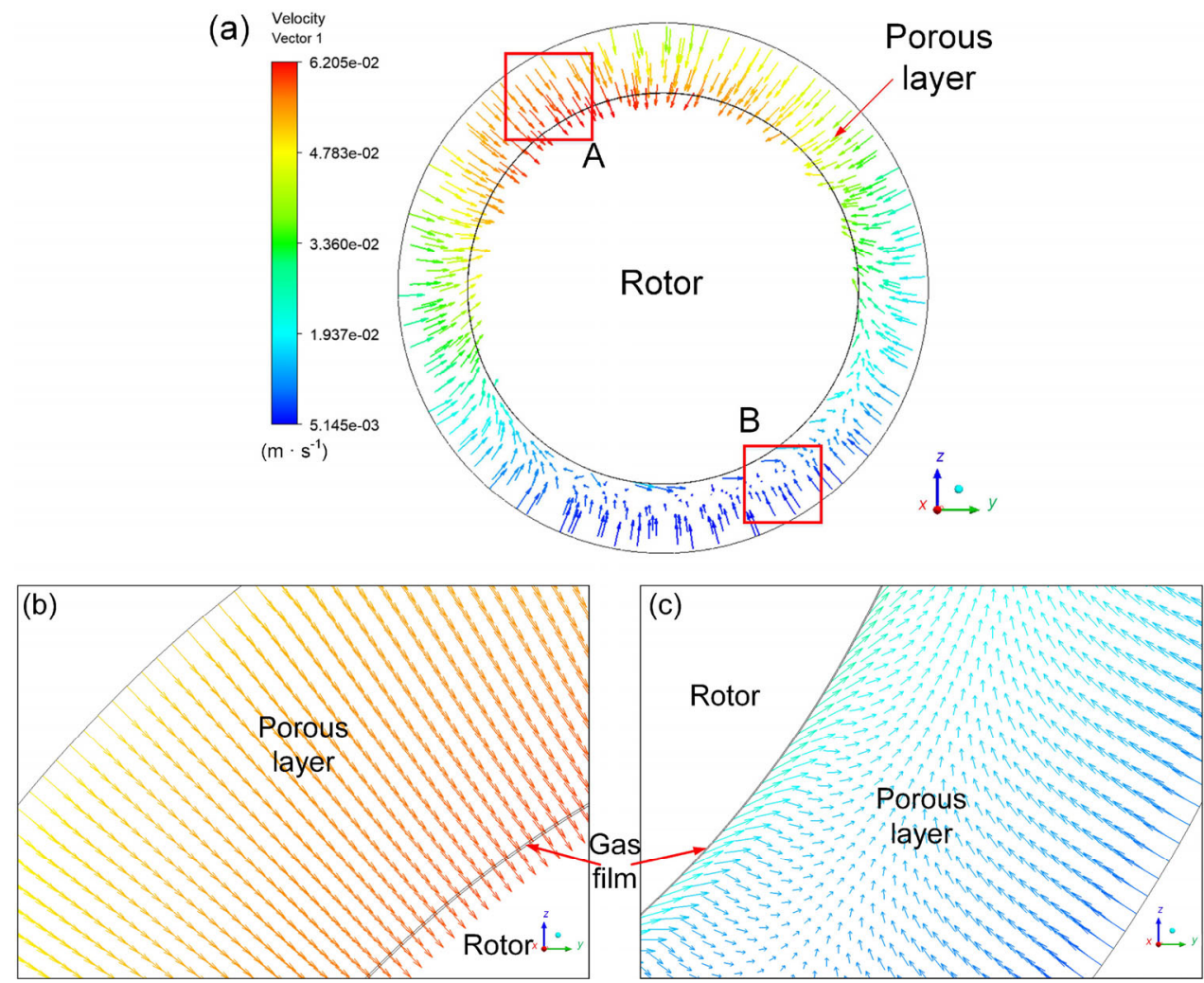

Fig. 9 Internal velocity vectors of PGB: (a) velocity vector; (b) view A; (c) view B.

plane. The direction of the flow velocity vectors is from either the porous layer into the film or in reverse. This illustrates that the internal flow of the PGB has a self-circulation. In the region where the gas film gap becomes larger, the pressure is lower, and the gas enters the gas film from the porous layer, as shown in detail in view A in Fig. 9. In the region where the gas film gap becomes smaller, the pressure is higher, and the gas flow enters the porous layer from the gas film, as shown in detail. View B in Fig. 9 indicates that the gas evenly enters the porous layer and meets the inlet gas, then flows along the circumferential direction of the porous layer, and finally enters the gas film again in the low-pressure region. A circulating flow indicates that the PGB is adaptive. The flow entering the porous layer can avoid an excessively high pressure to ensure that the rotor operates at a high position and reduces the unstable oscillation of the rotor $[52,53]$.

The inlet pressure of the porous layer is $0.5 \mathrm{MPa}$, the eccentricity is 0.5 , and the velocity distribution on the symmetric plane of the PGB under different speeds and permeability is shown in Fig. 10. It is useful to understand the relationship between the pressure drop, velocity direction, and magnitude by combining the velocity distribution with pressure distribution and velocity vector.

As shown in Figs. 10(c) and 10(d), as the permeability increases, the fluid velocity increases. The maximum velocity in Fig. 10(c) was $0.07012 \mathrm{~m} / \mathrm{s}$, whereas that in Fig. 10(a) was $0.06325 \mathrm{~m} / \mathrm{s}$. In addition, a high permeability is conducive to the circulation of airflow inside the PGB.

\section{Experiment and validation}

To verify the accuracy of the simulation model of the PGB with VSB. A test platform was designed. The load capacity and mass flow rate were obtained and compared with the simulation results at different speeds, gas supply pressures, and permeability.

\subsection{Test platform}

The test bench comprises a pedestal, two supports, an electric motor, a PGB to be tested, a loading mechanism, and a data acquisition system. Figure 11 shows the test platform. As a significant feature of the 
(a)

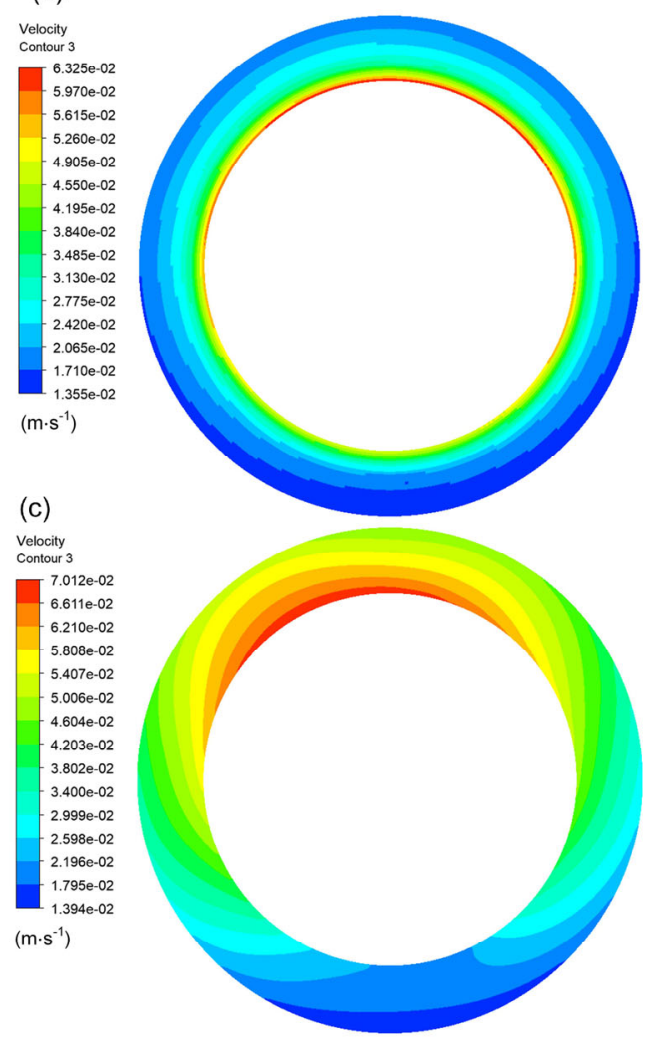

(b)

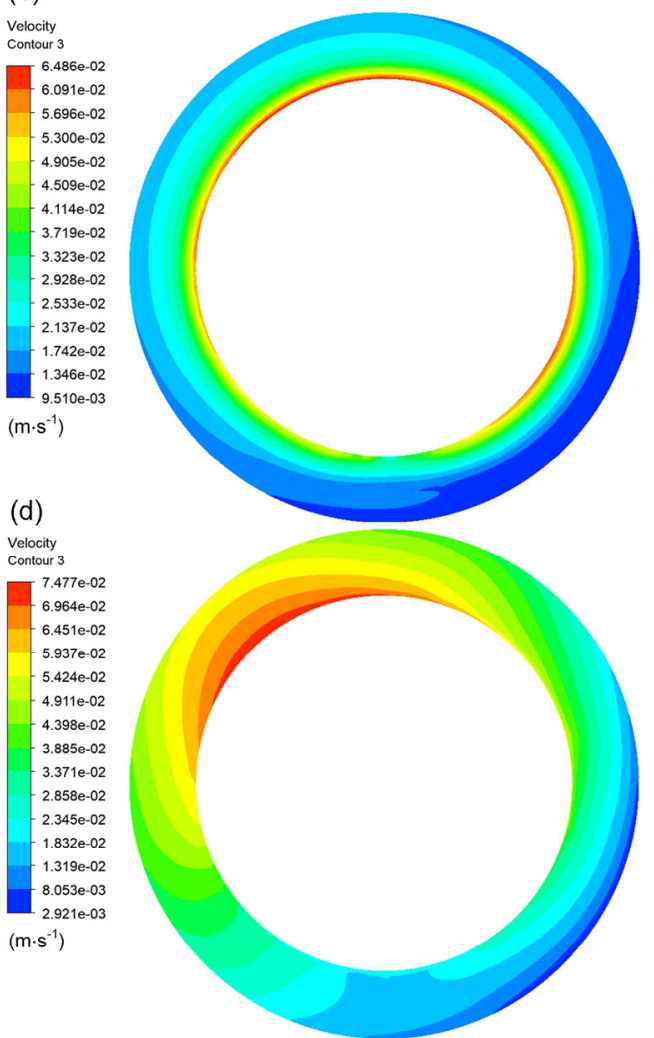

Fig. 10 Velocity distribution on symmetrical plane: (a) speed $=20,000 \mathrm{rpm}, K=1 \times 10^{-14} \mathrm{~m}^{2}$; (b) speed $=70,000 \mathrm{rpm}, K=1 \times 10^{-14} \mathrm{~m}^{2}$; (c) speed $=20,000 \mathrm{rpm}, K=1 \times 10^{-13} \mathrm{~m}^{2}$; (d) speed $=70,000 \mathrm{rpm}, K=1 \times 10^{-13} \mathrm{~m}^{2}$. As shown in Fig. 10(a), the high-speed rotor drives the gas in the gas film to rotate, forming a high-speed region around the rotor. In the eccentric direction, there exists a more significant low-velocity region. This is because more airflow is encountered in this region. Figure 10(b) displays a similar regulation to that shown in Fig.10(a); however, as the speed increases, the hydrodynamic pressure increases the overall pressure. More airflow enters the porous layer and pushes the low-velocity region outward. The low-velocity region also moves along the circumferential direction.

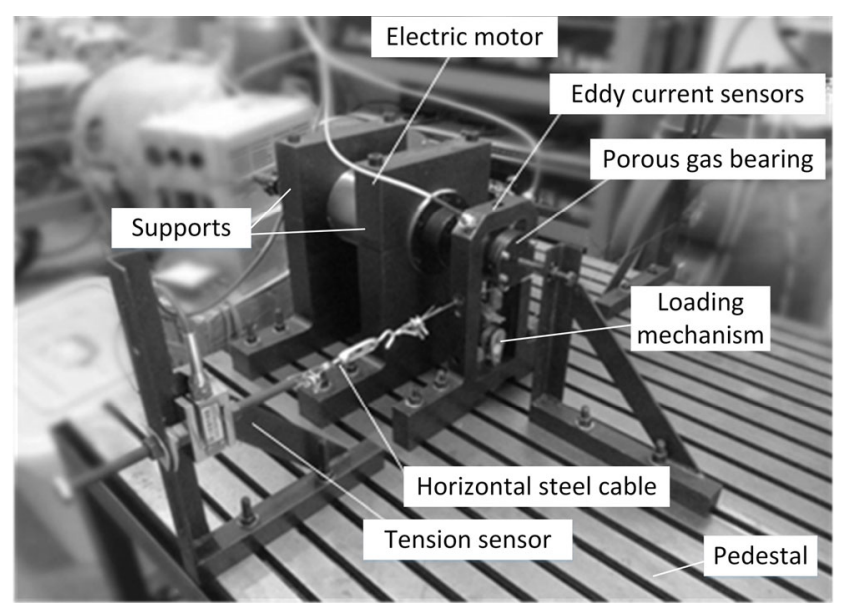

Fig. 11 Overall structures of PGB test platform.

test platform, the PGB and bearing seat are suspended for operation on the rotating rotor. The rotor is connected to a motor through a flexible coupling. A vertical rod was fixed on the bearing seat, and steel cable $\mathrm{B}$ connected the vertical rod to the tension sensor. The change in the bearing resistance moment is transformed into a change in the cable tension, which can be obtained by a tension sensor. During the test, the bearing friction can be determined, and the reasonable radial force loading can be determined by monitoring the variation in the resistance moment. Steel cable A was connected to the vertical rod through a pulley, and the other end was connected to a weight hanging basket. The radial force loaded on the bearing seat can be changed by changing the weight mass. The sum mass of the weight sets, bearing seat, and vertical rod is the load capacity of the bearing. Figures 12 and 13 show the tension sensor to measure the bearing resistance moment and the loading mechanism of the PGB test platform, respectively. As an advantage, it 


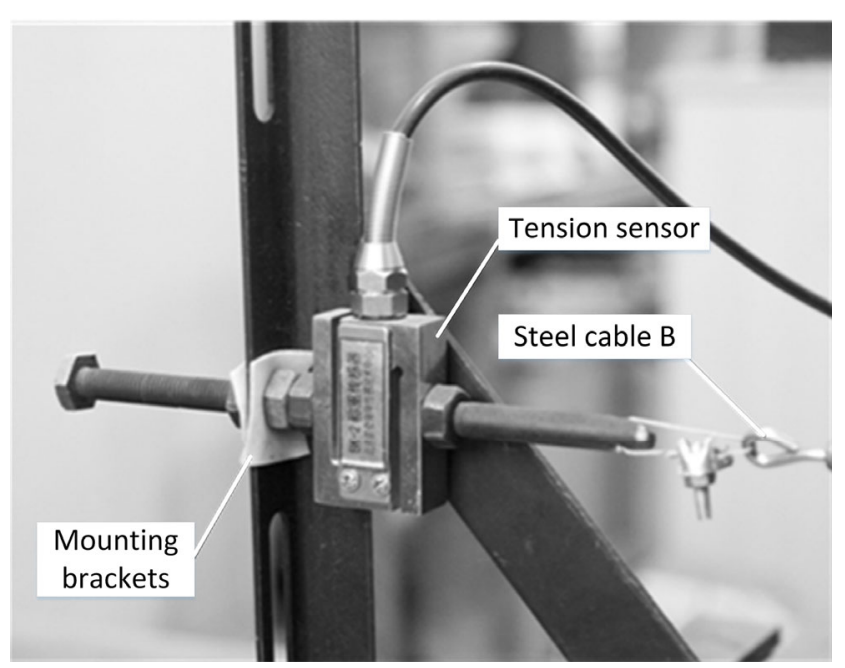

Fig. 12 Tension sensor.

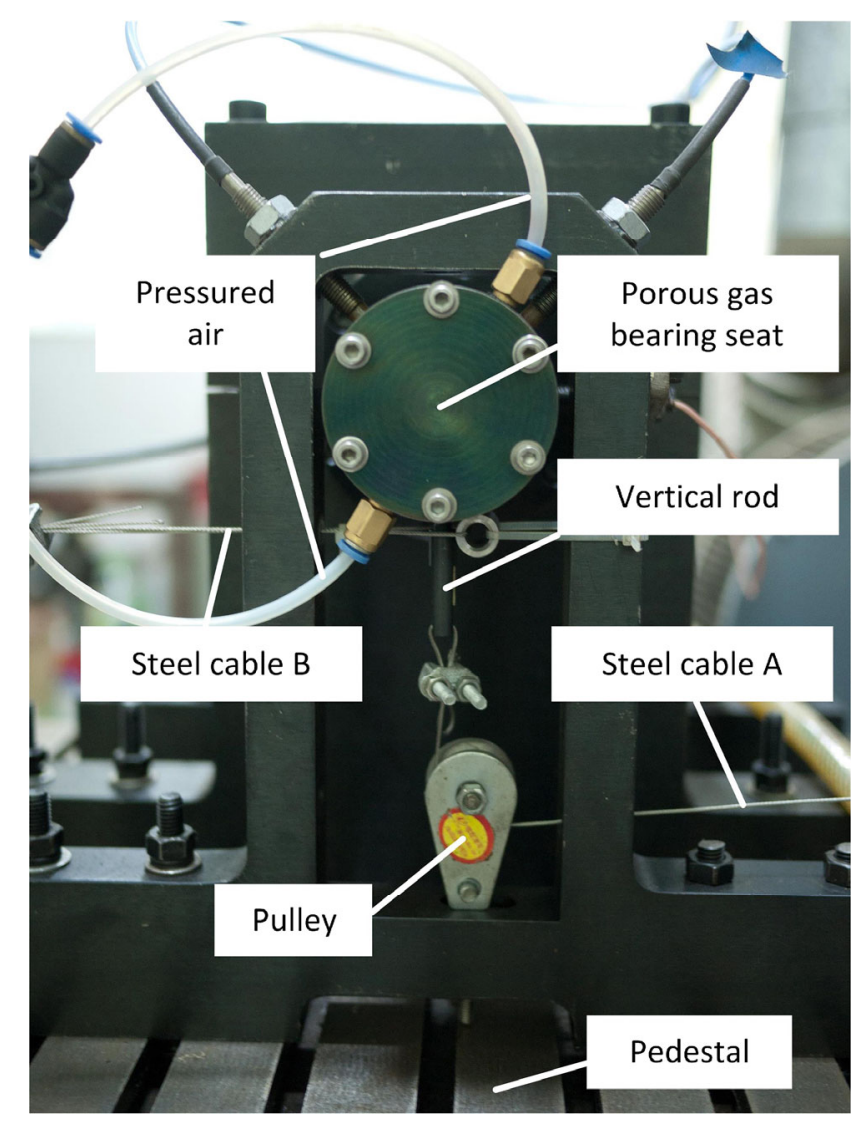

Fig. 13 Loading mechanism.

is convenient to apply a load to the bearing seat without affecting the operation of the bearing, which is entirely consistent with the actual bearing condition. This method makes it feasible to study the influence of the parameters on the load capacity.

Two HZ-8500 series eddy current displacement sensors within a range of $1 \mathrm{~mm}$, a nominal sensitivity of $8 \mathrm{mV} / \mu \mathrm{m}$, and an operating frequency of $5 \mathrm{kHz}$ were arranged orthogonally, as indicated in Fig. 14(a). LMS SC305 collects the bearing vibration and noise data to monitor the operating process $[54,55]$. Simultaneously, the test control platform gathers data such as the force, displacement, speed, and temperature, as shown in Fig. 14(b). The detailed parameters of the sensors used in the test platform are listed in Table 4.

\subsection{Test results and model validation}

The load capacity and mass flow rate are essential performances of the $\mathrm{PGB}$, which are directly related to the application range [56-58]. Determined by the specifications of the sensors, the maximum error of the load capacity measurement is $\pm 0.5 \%$, and the error of the mass flow rate measurement is no more than $\pm 1.5 \%$, which indicates a high-accuracy measurement. The simulation load capacity can be obtained by integrating the pressure on the rotor along the circumferential and axial directions. In this section, the experimental and simulation results, regarding whether or not to consider the VSB are compared. To evaluate the measurement uncertainty for the load capacity and mass flow rate, the method presented in Ref. [59] to determine the standard uncertainty was applied to the sensors. We repeated the test at least five times for each condition, and the average value was used to reduce the measurement uncertainties and avoid the contingency. The errors of multiple measurements of the load capacities and mass flow rate are influenced by a number of elemental error sources such as unsteadiness in the "steady-state" phenomenon being measured and errors caused by an imperfect installation of the transducer. For each operating condition, the standard uncertainty was quite small. Therefore, the measurements are considered to be precise and reliable. As shown in Figs. 15-18, the labels "TEST", "NVSB", and "VSB" represent the results of the experiment, the simulation neglecting the VSB, and the simulation considering the VSB, respectively.

The structure of the PGB remained unchanged, with a permeability of $1 \times 10^{-14} \mathrm{~m}^{2}$. Figure 15 shows the effect of the rotational speed on the load capacity under different inlet pressures. As the rotating speed 

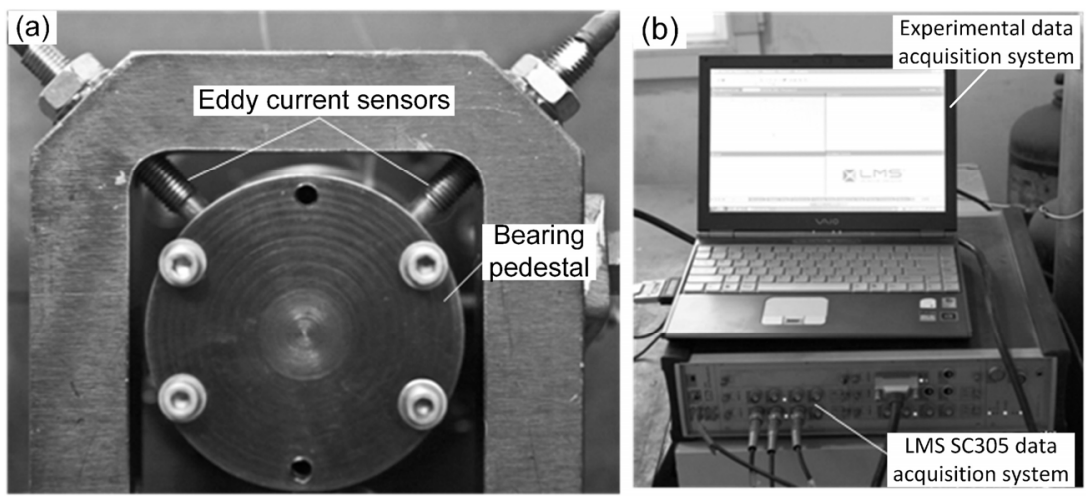

Fig. 14 Configuration of test platform: (a) the arrangement of eddy current sensors and (b) the experimental data acquisition system.

Table 4 Characteristics of the sensors.

\begin{tabular}{cccccc}
\hline Parameter & Sensor type & Measurement range & Precision & Resolution & Standard uncertainty \\
\hline Rotor speed & Eddy current & $0.2-200 \mathrm{krpm}$ & $\pm 0.2 \%$ & $0.2 \mathrm{krpm}$ & $0.5 \mathrm{krpm}$ \\
Gas pressure & Piezoresistive & $0.05-0.6 \mathrm{MPa}$ & $\pm 0.2 \%$ & $0.0005 \mathrm{MPa}$ & $0.0012 \mathrm{MPa}$ \\
Mass flow & MEMS & $0.5-50 \mathrm{~L} / \mathrm{min}$ & $\pm 1.5 \%$ & $0.1 \mathrm{~L} / \mathrm{min}$ & $0.3 \mathrm{~L} / \mathrm{min}$ \\
Temperature & Thermocouple & $0-500{ }^{\circ} \mathrm{C}$ & $\pm 0.2 \%$ & $0.1^{\circ} \mathrm{C}$ & $2{ }^{\circ} \mathrm{C}$ \\
Displacement & Eddy current & $1 \mathrm{~mm}$ & $\pm 0.1 \%$ & $1 \mu \mathrm{m}$ & $3 \mu \mathrm{m}$ \\
Vibration & Piezoelectric & $\pm 50 \mathrm{~g}$ & $1 \%$ & $0.004 \mathrm{~g}$ & $0.032 \mathrm{~g}$ \\
\hline
\end{tabular}

and inlet pressure increase, the load capacity increased. The load capacity exhibits an apparent upward trend after the rotational speed exceeds $6.5 \times 10^{4} \mathrm{rpm}$, indicating that the higher the speed, the faster the load capacity increases. In addition, the VSB results are extremely close to the TEST results, with an average error of $3.4 \%$, which demonstrates that the VSB has a high simulation accuracy. The velocity slip boundary condition can reflect the flow resistance in

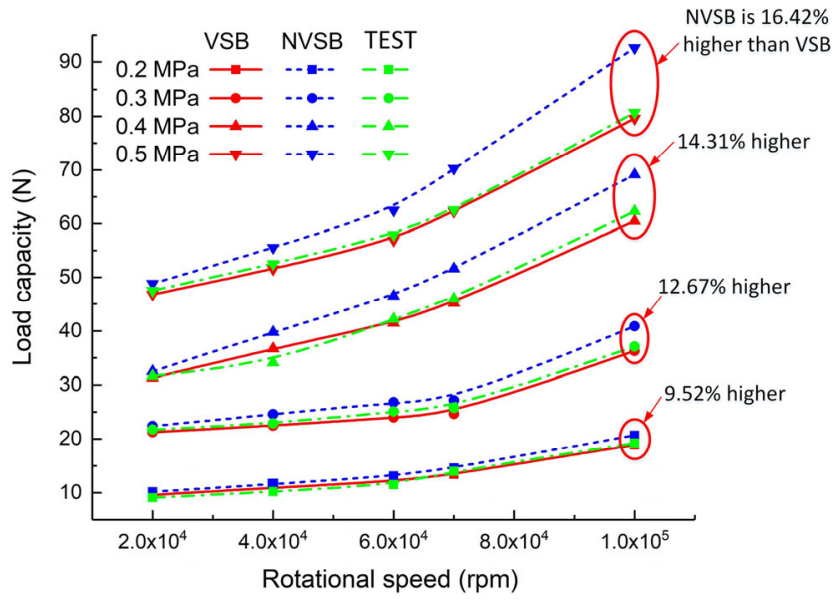

Fig. 15 Influence of inlet pressure on load capacity under different speeds. the gap between the PGB and the rotor. NVSB overrates the flow resistance, resulting in a $16.42 \%$ overestimation of the load capacity compared to the VSB.

Figure 16 depicts the effect of the rotating speed on the gas mass flow rate of the PGB at different inlet pressures. The larger the inlet pressure is, the higher the mass flow rate is. Under the same inlet pressure, the mass flow rate exhibited a downward trend with increasing speed. This indicates that the high rotating

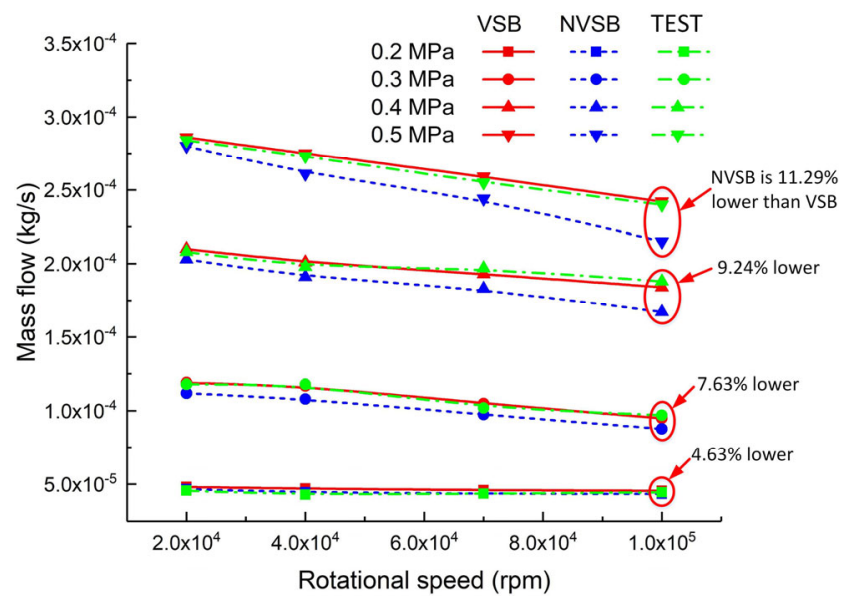

Fig. 16 Influence of inlet pressure on the mass flow rate under different speeds. 
speed at the outlet drives the gas flow to rotate and has a rotary sealing effect. Compared with the NVSB, the VSB is closer to the TEST results, indicating that the velocity slip boundary conditions improve the accuracy of the mass flow simulation. The mass flow rate of the NVSB was smaller than that of the VSB. As the inlet pressure and speed increased, the difference increased, reaching $11.29 \%$. The NVSB underestimated the mass flow of the bearings.

The inlet and outlet pressures are 0.5 and $0.1 \mathrm{MPa}$, respectively. Under different permeabilities of $1 \times 10^{-12}, 1 \times 10^{-13}$, and $1 \times 10^{-14} \mathrm{~m}^{2}$, the variation curves of the load capacity and mass flow rate with the rotating speed are as shown in Figs. 17 and 18, respectively.

Figure 17 shows the variation curves of the load capacity of the PGB with a rotating speed under different permeabilities. As the rotating speed increases,

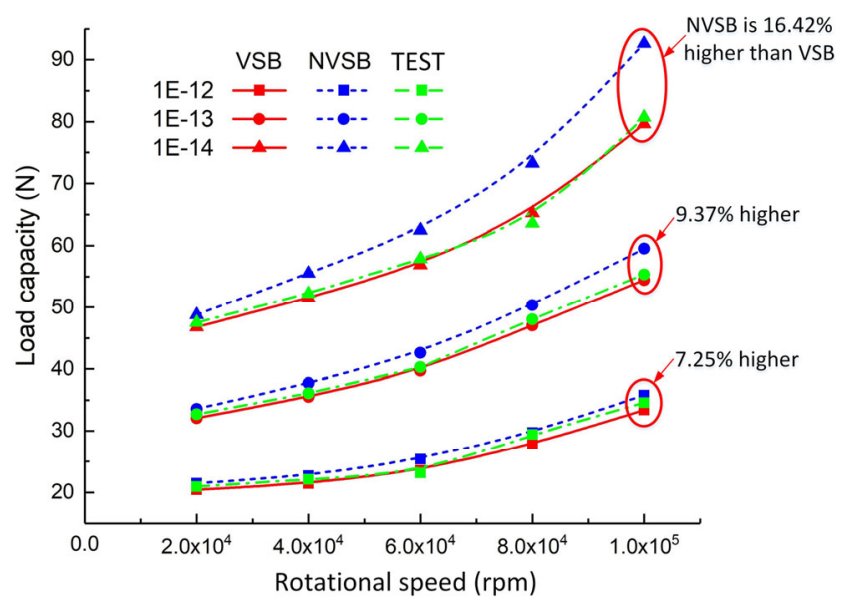

Fig. 17 Influence of permeability on load capacity under different speeds.

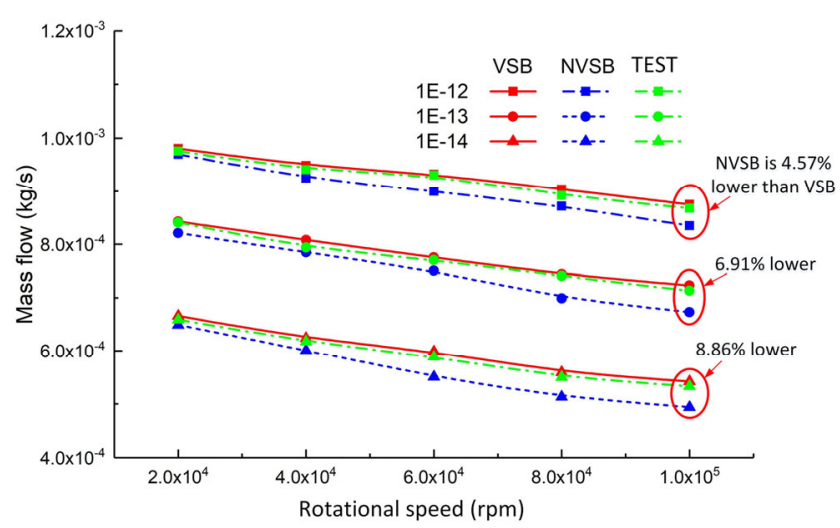

Fig. 18 Influence of permeability on mass flow rate under different speeds. the load capacity increased. The higher the rotating speed is, the higher the load capacity is. With a decrease in permeability from $1 \times 10^{-12}$ to $1 \times 10^{-14} \mathrm{~m}^{2}$, the load capacity increases, as shown in Fig. 17. Compared with NVSB, the load capacity of the VSB and TEST results shows a fine consistency, which proves that the simulation model of the velocity slip is more accurate and can estimate the performance under different speeds. The load capacity of NVSB was higher than that of VSB, and the difference increased from $7.25 \%$ to $16.42 \%$ with a decrease in permeability from $1 \times 10^{-12}$ to $1 \times 10^{-14} \mathrm{~m}^{2}$. This means that the NVSB overestimates the load capacity. At a high permeability of $1 \times 10^{-12} \mathrm{~m}^{2}$, the radial flow plays a leading role, which reduces the load capacity and weakens the effect of a velocity slip.

Figure 18 indicates the variation curves of the mass flow rate of the PGB with the rotating speed under different levels of permeability. The mass flow rate tends to decline with an increase in the rotating speed, which shows hydrodynamic pressure sealing. Owing to the increase in the permeability, the ability of the gas to pass through the porous layer improves, and thus the mass flow rate increases. Compared with NVSB, the mass flow rate of VSB and TEST results is more consistent with each other and is smaller than that of VSB. The difference increases from $4.57 \%$ to $8.86 \%$ with a decrease in permeability from $1 \times 10^{-12}$ to $1 \times 10^{-14} \mathrm{~m}^{2}$. By contrast, the NVSB underestimates the mass flow rate.

\section{Conclusions}

This study investigated the gas lubrication performance of PGB and analyzed the flow characteristics, pressure distribution, velocity distribution, and velocity vector in the fluid domain under different speeds, inlet gas pressures, and levels of permeability. A model of the PGB with a Maxwell velocity slip boundary condition is built by combining the Darcy-Forchheimer laws and modified Navier-Stokes equations. An experimental platform is presented. An experiment was conducted to compare the simulation results. The main conclusions are as follows:

1) Compared with the rotational speed and permeability, the inlet pressure has the most significant 
influence on the load capacity. When the inlet pressure is increased from 0.2 to $0.5 \mathrm{MPa}$ (a 2.5-fold increase) at $1 \times 10^{5} \mathrm{rpm}$, the load capacity is increased 5-fold from 15 to $76 \mathrm{~N}$. The effective way to improve the load capacity of the PGB is to increase the inlet pressure, which is feasible.

2) The maximum pressure of the gas film increases from 0.31 to $0.50 \mathrm{MPa}$ with an increase in permeability from $1 \times 10^{-14}$ to $1 \times 10^{-12} \mathrm{~m}^{2}$, whereas the load capacity decreases as the permeability increases. This is because the flow resistance decreases with an increase in permeability, which allows a quick escape of gas. Thus, the mass flow rate increases and the pressure difference on the rotor surface decreases, and therefore the load capacity decreases.

3) The flow fields in the porous layer and gas film were visualized. The gas can enter the porous layer from the gas film region and flow circumferentially inside the porous layer.

4) The average error between the VSB and TEST results is within $3.4 \%$. This indicates that the simulation model incorporating the velocity slip boundary has a higher accuracy. The NVSB overrated the load capacity by $16.42 \%$ and undervalued the mass flow rate by $11.29 \%$.

Finally, in the small gap between the PGB and rotor, the Knudsen number is within the slip region, and the velocity slip boundary conditions need to be considered, which can improve the accuracy of the numerical model and is quite beneficial for correctly evaluating the performance of the PGB. Bearing manufacturers can use this research to further extend the practical applications of the PGBs.

\section{Acknowledgements}

This study was funded by the National Natural Science Foundation of China (Grant Nos. 51775025 and 51175018), China Automobile Industry Innovation and Development Joint Fund (Grant No. U1664257), China Key Research and Development plan (Grant Nos. 2017YFB0102102 and 2018YFB0104100), and the Beijing Natural Science Foundation (Grant No. 3113030).

Open Access This article is licensed under a Creative
Commons Attribution 4.0 International License, which permits use, sharing, adaptation, distribution and reproduction in any medium or format, as long as you give appropriate credit to the original author(s) and the source, provide a link to the Creative Commons licence, and indicate if changes were made.

The images or other third party material in this article are included in the article's Creative Commons licence, unless indicated otherwise in a credit line to the material. If material is not included in the article's Creative Commons licence and your intended use is not permitted by statutory regulation or exceeds the permitted use, you will need to obtain permission directly from the copyright holder.

To view a copy of this licence, visit http://creativecommons.org/licenses/by/4.0/.

\section{References}

[1] Feng K, Wu Y H, Liu W H, Zhao X Y, Li W J. Theoretical investigation on porous tilting pad bearings considering tilting pad motion and porous material restriction. Precis Eng 53: 26-37 (2018)

[2] Wu Y H, Feng K, Zhang Y, Liu W H, Li W J. Nonlinear dynamic analysis of a rotor-bearing system with porous tilting pad bearing support. Nonlinear Dyn 94(2): 1391-1408 (2018)

[3] Kumar V. Porous metal bearings - A critical review. Wear 63(2): 271-287 (1980)

[4] Sneck H J. A survey of gas-lubricated porous bearings. $J$ Lubr Technol 90(4): 804-809 (1968)

[5] Majumdar B C. Gas-lubricated porous bearings: A bibliography. Wear 36(3): 269-273 (1976)

[6] Heller S, Shapiro W, Decker O. A porous hydrostatic gas bearing for use in miniature turbomachinery. SL E Trans 14(2): 144-155 (1971)

[7] Devitt D, San A L, Jeung SH.Carbon-graphite gas bearings for turbomachinery. In Proceedings of the 30th ASPE Annual Meeting, Hyatt Regency Austin, Austin, USA, 2015: 218-222.

[8] Information. https://www.newwayairbearings.com/technology/ technical-resources/new-way-techincal-reports/technicalreport-6-air-bearings-for-high-power-turbomachinery/, 2014.

[9] Lee C C, You H I. Geometrical design considerations on externally pressurized porous gas bearings. Tribol Trans 53(3): 386-391 (2010)

[10] Lee C C, You H I. Characteristics of externally pressurized porous gas bearings considering structure permeability. Tribol Trans 52(6): 768-776 (2009) 
[11] Chang C W, Chen C K. Chaotic response and bifurcation analysis of a flexible rotor supported by porous and nonporous bearings with nonlinear suspension. Nonlinear Anal: Real World Appl 10(2): 1114-1138 (2009)

[12] Cui H L, Wang Y, Yue X B, Huang M, Wang W. Effects of manufacturing errors on the static characteristics of aerostatic journal bearings with porous restrictor. Tribol Int 115: 246-260 (2017)

[13] Cui H L, Wang Y, Yue X B, Huang M, Wang W, Jiang Z Y. Numerical analysis and experimental investigation into the effects of manufacturing errors on the running accuracy of the aerostatic porous spindle. Tribol Int 118: 20-36 (2018)

[14] Kurotani Y, Tanaka H. A novel physical mechanism of liquid flow slippage on a solid surface. Sci Adv 6(13): eaaz0504 (2020)

[15] Nicoletti R, Silveira Z C, Purquerio B M. Modified Reynolds equation for aerostatic porous radial bearings with quadratic forchheimer pressure-flow assumption. J Tribol 130(3): 031701 (2008)

[16] Rao T V V L N, Rani A M A, Awang M, Nagarajan T, Hashim F M. Stability analysis of double porous and surface porous layer journal bearing. Tribol - Mater Surfaces Interfaces 10(1): 19-25 (2016)

[17] Prakash J, Gururajan K. Effect of velocity slip in an infinitely long rough porous journal bearing. Tribol Trans 42(3): 661-667 (1999)

[18] Kalavathi G K, Dinesh P A, Gururajan K. Influence of roughness on porous finite journal bearing with heterogeneous slip/no-slip surface. Tribol Int 102: 174-181 (2016)

[19] Le N T P, Roohi E, Tran T N. Comprehensive assessment of newly-developed slip-jump boundary conditions in highspeed rarefied gas flow simulations. Aerosp Sci Technol 91 : 656-668 (2019)

[20] Jebauer S, Czerwińska J. Implementation of Velocity Slip and Temperature Jump Boundary Conditions for Microfluidic Devices. Warsaw (Poland): Instytut Podstawowych Problemów Techniki PAN, 2007.

[21] Su J C T, You H I, Lai J X. Numerical analysis on externally pressurized high-speed gas-lubricated porous journal bearings. Ind Lubr Tribol 55(5): 244-250 (2003)

[22] Wang N Z, Chen H Y. A two-stage multiobjective optimization algorithm for porous air bearing design. Tribol Int 93: 355-363 (2016)

[23] Jiang S Y, Lin S Y, Xu C D. Static and dynamic characteristics of externally pressurized porous gas journal bearing with four degrees-of-freedom. J Tribol 140(1): 011702 (2018)

[24] Cui Y W. Thermal characteristic analysis and rotordynamic experimental study of aerostaticporous journal bearings.
Ph.D. Thesis. Changsha (China): Hunan University, 2017.

[25] Saha N, Majumdar B C. Study of externally-pressurized gas-lubricated two-layered porous journal bearings: A steady state analysis. Proc Inst Mech Eng Part J: J Eng Tribol 216(3): 151-158 (2002)

[26] Paidoussis M, Price S, de Langre E. Fluid-structure Interactions. Cambridge (UK): Cambridge University Press, 2009.

[27] Ji F Z, Bao Y P, Zhou Y, Du F R, Zhu H J, Zhao S, Li G, Zhu $X$ F, Ding $S \mathrm{~T}$. Investigation on performance and implementation of Tesla turbine in engine waste heat recovery. Energy Convers Manag 179: 326-338 (2019)

[28] Jin Y Z, Chen F, Xu J M, Yuan X Y. Nonlinear dynamic analysis of low viscosity fluid-lubricated tilting-pad journal bearing for different design parameters. Friction 8(5): 930-944 (2020)

[29] Hu Y Q, Meng Y G. Numerical modeling and analysis of plasmonic flying head for rotary near-field lithography technology. Friction 6(4): 443-456 (2018)

[30] Lin W. A slip model for rarefied gas flows at arbitrary Knudsen number. Appl Phys Lett 93(25): 253103 (2008)

[31] Liang H, Guo D, Luo J B. Film forming behavior in thin film lubrication at high speeds. Friction 6(2): 156-163 (2018)

[32] Zhang S H, Qiao Y J, Liu Y H, Ma L R, Luo J B. Molecular behaviors in thin film lubrication-Part one: Film formation for different polarities of molecules. Friction 7(4): 372-387 (2019)

[33] Tang Z Q, Zhou D D, Jia T, Pan D, Zhang C W. Investigation of lubricant transfer and distribution at head/disk interface in air-helium gas mixtures. Friction 7(6): 564-571 (2019)

[34] Ma L R, Luo J B. Thin film lubrication in the past 20 years. Friction 4(4): 280-302 (2016)

[35] Gao M, Li H Y, Ma L R, Gao Y, Ma L W, Luo J B. Molecular behaviors in thin film lubrication-Part two: Direct observation of the molecular orientation near the solid surface. Friction 7(5): 479-488 (2019)

[36] Beskok A, Karniadakis G E, Trimmer W. Rarefaction and compressibility effects in gas microflows. J Fluids Eng 118(3): 448-456 (1996)

[37] Bailey NY, Hibberd S, Power H. Evaluation of the minimum face clearance of a high-speed gas-lubricated bearing with Navier slip boundary conditions under random excitations. J Eng Math 112(1): 17-35 (2018)

[38] Zhang X B, Ding S T, Du F R, Ji F Z, Guo S G. Numerical simulation on aerodynamic performance of ram air turbine based on mixed flow field. In Proceedings of the ASME 2018 International Mechanical Engineering Congress and Exposition, Pittsburgh, PA, USA, 2018: 88304. 
[39] Zhu J C, Chen H, Chen X D. Large eddy simulation of vortex shedding and pressure fluctuation in aerostatic bearings. J Fluids Struct 40: 42-51 (2013)

[40] Wang W, He Y Y, Zhao J, Mao J Y, Hu Y T, Luo J B. Optimization of groove texture profile to improve hydrodynamic lubrication performance: Theory and experiments. Friction 8(1): 83-94 (2020)

[41] Leclercq T, de Langre E. Vortex-induced vibrations of cylinders bent by the flow. J Fluids Struct 80: 77-93 (2018)

[42] Ji F Z, Zhang X B, Du F R, Ding S T, Zhao Y H, Xu Z, Wang Y, Zhou Y. Experimental and numerical investigation on micro gas turbine as a range extender for electric vehicle. Appl Therm Eng 173: 115236 (2020)

[43] Oshkai P, Velikorodny A. Flow-acoustic coupling in coaxial side branch resonators with rectangular splitter plates. J Fluids Struct 38: 22-39 (2013)

[44] Lam K, Lin Y F, Zou L, Liu Y. Investigation of turbulent flow past a yawed wavy cylinder. J Fluids Struct 26(7-8): 1078-1097 (2010)

[45] Zhang W M, Yan H, Peng Z K, Meng G. Finite volume modeling of gas flow in microbearings with rough surface topography. Tribol Trans 59(1): 99-107 (2016)

[46] Ji F Z, Pan Y, Zhou Y, Du F R, Zhang Q, Li G. Energy recovery based on pedal situation for regenerative braking system of electric vehicle. Veh Syst Dyn 58(1): 144-173 (2020)

[47] Cha M, Glavatskih S. Nonlinear dynamic behaviour of vertical and horizontal rotors in compliant liner tilting pad journal bearings: Some design considerations. Tribol Int 82: 142-152 (2015)

[48] $\mathrm{Wu} \mathrm{Y} \mathrm{H.} \mathrm{Theoretical} \mathrm{analysis} \mathrm{and} \mathrm{experimental} \mathrm{investigation}$ on rotordynamic performance of a rigid rotor supported on porous tiliting pad bearings. Ph.D. Thesis. Changsha (China): Hunan University, 2019.

[49] Cui H L. Study on the influence mechanism of the dynamic characteristics of porous aerostatic bearings. Ph.D. Thesis.

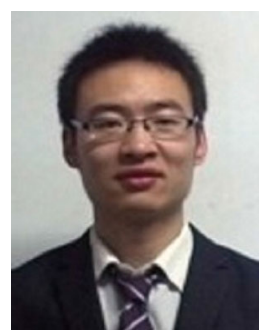

Xiangbo ZHANG. He received his B.S. degree from Henan University of Science and Technology in 2012. He is currently a Ph.D. student at the School of Energy and Power
Mianyang (China): China Academy of Engineering Physics, 2018.

[50] Wu Y S, Pruess K, Persoff P. Gas flow in porous media with klinkenberg effects. Transp Porous Media 32(1): 117-137 (1998)

[51] Joseph J, Kuntikana G, Singh D N. Investigations on gas permeability in porous media. J Nat Gas Sci Eng 64: 81-92 (2019)

[52] Balasoiu A M, Braun M J, Moldovan S I. A parametric study of a porous self-circulating hydrodynamic bearing. Tribol Int 61: 176-193 (2013)

[53] Zhou Y, Xing T, Song Y, Li Y J, Zhu X F, Li G, Ding S T. Digital-twin-driven geometric optimization of centrifugal impeller with free-form blades for five-axis flank milling. J Manuf Syst 58: 22-35 (2021)

[54] Wu J, Wen B, Zhou Y, Zhang Q, Ding S T, Du F R, Zhang S G. Eddy current sensor system for blade tip clearance measurement based on a speed adjustment model. Sensors 19(4): 761 (2019)

[55] Xu Z, Ji F Z, Ding S T, Zhao Y H, Zhang X B, Zhou Y, Zhang Q, Du F R. High-altitude performance and improvement methods of poppet valves 2-stroke aircraft diesel engine. Appl Energy 276: 115471 (2020)

[56] Zhou Y, Shao L T, Zhang C, Ji F Z, Liu J, Li G, Ding S T, Zhang Q, Du F R. Numerical and experimental investigation on dynamic performance of bump foil journal bearing based on journal orbit. Chinese J Aeronaut 34(2): 586-600 (2021)

[57] Hsu T C, Chen J H, Chiang H L, Chou T L. Lubrication performance of short journal bearings considering the effects of surface roughness and magnetic field. Tribol Int 61: 169-175 (2013)

[58] Xu Z, Ji F Z, Ding S T, Zhao Y H, Zhou Y, Zhang Q, Du F R. Digital twin-driven optimization of gas exchange system of 2-stroke heavy fuel aircraft engine. J Manuf Syst 58: 132-145 (2021)

[59] Information. https://www.iso.org/standard/50461.html, 1995.

Engineering, Beihang University, China. His research is related to power machinery and engineering, including high-speed rotor system and micro gas turbine engine. 


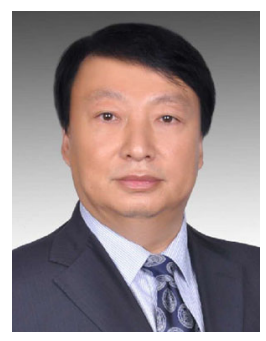

Shuiting DING. He received his B.S. degree in thermal engine power from Beihang University in 1990, and his Ph.D. degree in aerospace propulsion theory and engineering

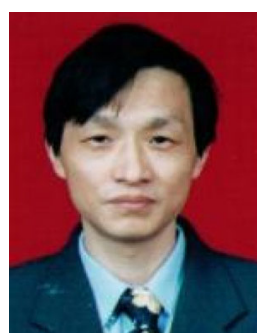

Farong DU. He received his B.S. degree from Henan University of Science and Technology in 1984. He is currently an associated professor

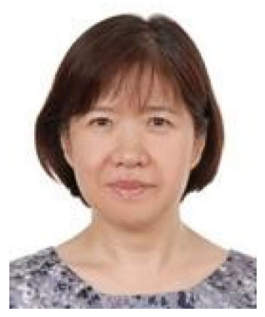

Fenzhu JI. She received her Ph.D. degree in vehicle engineering from Beihang University in 2006. She is currently an associated professor

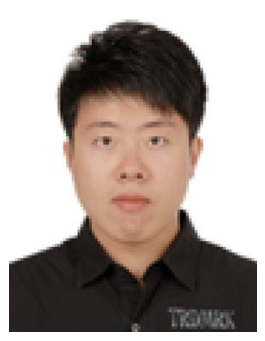

Zheng XU. He received his B.S. degree in thermal energy and power engineering from Beihang University in 2014. He is currently

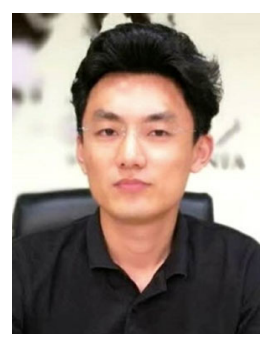

Jiang LIU. He received his Ph.D. degree in vehicle engineering from Beihang university in 2013. He is from Beihang University in 1998. He is currently a professor in Beihang University. His research interests include aviation engine system safety and airworthiness, air system of aero engine, and new energy system.

in Beihang University. His research interests include aviation power system, high-speed rotor system, and micro gas turbine engine.

in Beihang University. Her research interests include automobile engine design theory \& design method and new energy electric vehicle design technology.

a Ph.D. student in power machinery and engineering in Beihang University. His research interests include aviation power system, power characteristics at high altitude, and engine gas exchange process.

currently a CEO in Richen Power. His research interests include micro-hybird aviation power system. 


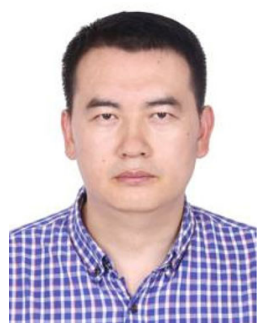

Qi ZHANG. He received his B.S. degree from University of Electronic Science and Technology of China in 2001, and his Ph.D. degree in vehicle engineering from Beihang
University in 2015. He is currently a lecturer in Beihang University. His research interests include micro-hybird aviation power system, brushless DC motor drive, and generator rectification.

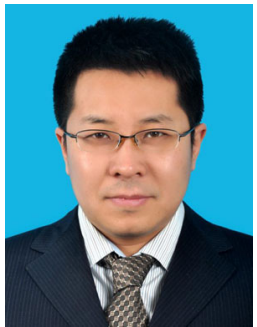

Yu ZHOU. He received his B.S. degree in transportation science from Harbin Institute of Technology in 2003, and his Ph.D. degree in vehicle engineering from Beihang
University in 2007. He is currently an associated professor in Beihang University. His research interests include high-speed rotor system dynamics and aerodynamic thermal characteristics. 